\title{
A coupled physical-biological model of the Northern Gulf of Mexico shelf: model description, validation and analysis of phytoplankton variability
}

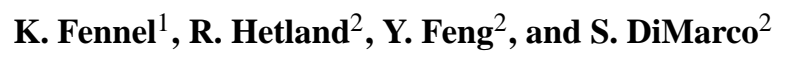 \\ ${ }^{1}$ Department of Oceanography, Dalhousie University, Halifax, Nova Scotia, Canada \\ ${ }^{2}$ Department of Oceanography, Texas A\&M University, College Station, Texas, USA \\ Received: 16 December 2010 - Published in Biogeosciences Discuss.: 7 January 2011 \\ Revised: 7 June 2011 - Accepted: 30 June 2011 - Published: 13 July 2011
}

\begin{abstract}
The Texas-Louisiana shelf in the Northern Gulf of Mexico receives large inputs of nutrients and freshwater from the Mississippi/Atchafalaya River system. The nutrients stimulate high rates of primary production in the river plume, which contributes to the development of a large and recurring hypoxic area in summer, but the mechanistic links between hypoxia and river discharge of freshwater and nutrients are complex as the accumulation and vertical export of organic matter, the establishment and maintenance of vertical stratification, and the microbial degradation of organic matter are controlled by a non-linear interplay of factors. Unraveling these interactions will have to rely on a combination of observations and models. Here we present results from a realistic, 3-dimensional, physical-biological model with focus on a quantification of nutrient-stimulated phytoplankton growth, its variability and the fate of this organic matter. We demonstrate that the model realistically reproduces many features of observed nitrate and phytoplankton dynamics including observed property distributions and rates. We then contrast the environmental factors and phytoplankton source and sink terms characteristic of three model subregions that represent an ecological gradient from eutrophic to oligotrophic conditions. We analyze specifically the reasons behind the counterintuitive observation that primary production in the light-limited plume region near the Mississippi River delta is positively correlated with river nutrient input, and find that, while primary production and phytoplankton
\end{abstract}

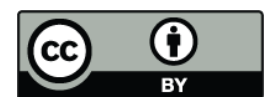

Correspondence to: K. Fennel (katja.fennel@dal.ca) biomass are positively correlated with nutrient load, phytoplankton growth rate is not. This suggests that accumulation of biomass in this region is not primarily controlled bottom up by nutrient-stimulation, but top down by systematic differences in the loss processes.

\section{Introduction}

The Texas-Louisiana shelf in the Northern Gulf of Mexico is dominated by large seasonal inputs of freshwater and inorganic and organic nutrients from the Mississippi/Atchafalaya River system. The Mississippi River is one of the world's major rivers; it has the third largest drainage basin, is the fifth largest in terms of freshwater discharge and seventh largest in terms of sediment discharge compared with other world rivers (Milliman and Meade, 1983). The Mississippi River drains $41 \%$ of the contiguous USA, including agricultural land in Southern Minnesota, Iowa, Illinois and Ohio, which contributes about one third of the nitrogen loading of the river (Goolsby et al., 2000). The greatest nitrogen loading comes from tile-drained fields in the cornbelt of the midwest (David et al., 2010). The mean annual nitrogen load to the Gulf of Mexico of $1.5 \mathrm{Mt} \mathrm{yr}^{-1}$ consists of approximately $61 \%$ nitrate, $37 \%$ organic nitrogen and $2 \%$ ammonium (1980-1996 mean), and the nitrate load has approximately tripled from 1970 to the late 90ies (Goolsby et al., 2000).

The large nutrient input from the Mississippi River stimulates phytoplankton growth, which contributes to the development of a large recurring hypoxic area on the TexasLouisiana shelf in summer (Rabalais et al., 2002). The

Published by Copernicus Publications on behalf of the European Geosciences Union. 
classic concept of coastal eutrophication leading to hypoxia and often applied to this region is as follows. Inorganic nutrients from the Mississippi fuel high rates of primary production as the discharged river water spreads in buoyant plumes over the shelf, and, as this organic matter sinks below the pycnocline and is respired microbially, oxygen consumption exceeds supply in bottom waters and hypoxia develops. The existence of statistically significant relationships between the annual Mississippi River nitrogen load and the spatial extent of the hypoxic area in summer (Turner et al., 2005; Greene et al., 2009) is consistent with this view. Also, a significant statistical relationship between nitrogen load and primary production was reported for the plume region near the Mississippi delta (Lohrenz et al., 1997) and is often interpreted in support of the classical concept.

However, a number of findings and ideas have been articulated recently that suggest the classic concept is too simplistic and that other factors are important as well (Rowe and Chapman, 2002; Hetland and DiMarco, 2008; Sylvan et al., 2006; Bianchi et al., 2010; Lehrter et al., 2009). For example, terrestrial organic matter load probably contributes significantly to oxygen consumption (Bianchi et al., 2010, 2009), stratification is important for hypoxia formation in preventing supply of oxygen below the pycnocline (Wiseman et al., 1997), sediment oxygen demand is not directly related to river nutrient load (Morse and Rowe, 1999; Rowe and Chapman, 2002), and spatially varying rates of macrozooplankton grazing affect the rate of phytoplankton accumulation and the amount of organic matter reaching the bottom (Dagg, 1995). Walker and Rabalais (2006) found no significant relationship between satellite-derived surface chlorophyll and hypoxia development. Lehrter et al. (2009), while confirming the existence of a statistically significant relationship between nutrient load and primary production in the plume near the Mississippi River delta, found no significant relationship between nutrient load and shelf-wide primary production.

Clearly, the mechanistic link between inorganic river nitrogen loads and hypoxia is not direct as the accumulation of phytoplankton biomass, the sinking of organic matter, the establishment and maintenance of vertical stratification, and the microbial degradation of organic matter are controlled by an interplay of factors and can interact in non-linear ways. Here we focus on the quantification of nutrient-stimulated primary production and the fate of this organic matter (i.e. its losses) across a gradient from highly eutrophic waters near the river delta to oligotrophic waters downstream of the nutrient sources.

Numerical models are invaluable tools for assessing the combined effects of these processes and for untangling their relative importance (see recent review by Peña et al., 2010). Green et al. (2008) and Eldridge and Roelke (2010) developed ecosystem models for the Mississippi River plume to investigate the response of organic matter production and sedimentation to variable loadings of nitrate and freshwater. Their models are embedded in idealized physical frameworks, but the importance of coupling with more realistic physics is emphasized in both studies. Here we present results from an ecosystem model that is coupled to a realistic 3-dimensional circulation model (Hetland and DiMarco, 2008). Although dissolved oxygen is not explicitly considered here, the model includes the water column processes that are considered to be of first order importance for hypoxia formation, namely river sources of organic and inorganic nitrogen, which enter the model through the Mississippi River delta and Atchafalaya Bay, light- and nutrientdependent phytoplankton production, zooplankton grazing, sinking of organic matter, microbial respiration, and a realistic and dynamic representation of horizontal and vertical advection and mixing processes. We present a 15 -yr simulation (from January 1990 to December 2004) comparing simulated distributions of nitrate and chlorophyll and modelpredicted rates with available observations. The simulation period overlaps with several observational programs, including the NOAA/NECOP program (1991-1993), which provides estimates of primary production, phytoplankton growth rates, zooplankton grazing rates and sedimentation fluxes, a NOAA-funded program from 2001 to 2004 that provides surface nitrate distributions (Sylvan et al., 2006), and the SeaWiFS program which provides estimates of surface chlorophyll (starting from the end of 1998). After demonstrating that the model realistically reproduces many observed features of nitrate and phytoplankton dynamics, we analyze the environmental differences and phytoplankton source and sink terms along the ecological gradient from high-nutrient plume waters to low-nutrient waters far from the direct influence of the Mississippi River. We find that spatial differences in phytoplankton loss terms, rather than growth rates, lead to the markedly different phytoplankton accumulation rates and standing stocks along this gradient. We also investigate the question why primary production rates in the plume region are correlated with nitrogen concentrations and river nitrate loads, even though primary production is light-limited in this region (nutrient concentrations never drop near limiting concentrations) and, hence, should not be sensitive to variations in nutrient concentrations and nutrient load.

\section{Model description}

\subsection{Physical model}

We use a configuration of the Regional Ocean Modeling System (Haidvogel et al., 2008, ROMS, http://myroms.org) for the Mississippi/Atchafalaya outflow region; the domain and topography are shown in Fig. 1. The model grid has 20 vertical, terrain-following layers with increased resolution near the surface and bottom. The horizontal resolution is highest near the Mississippi Delta with up to $1 \mathrm{~km}$ and lowest in the southwestern corner with $\sim 20 \mathrm{~km}$; the time step is about $1 \mathrm{~min}$. The details of the physical model are described 


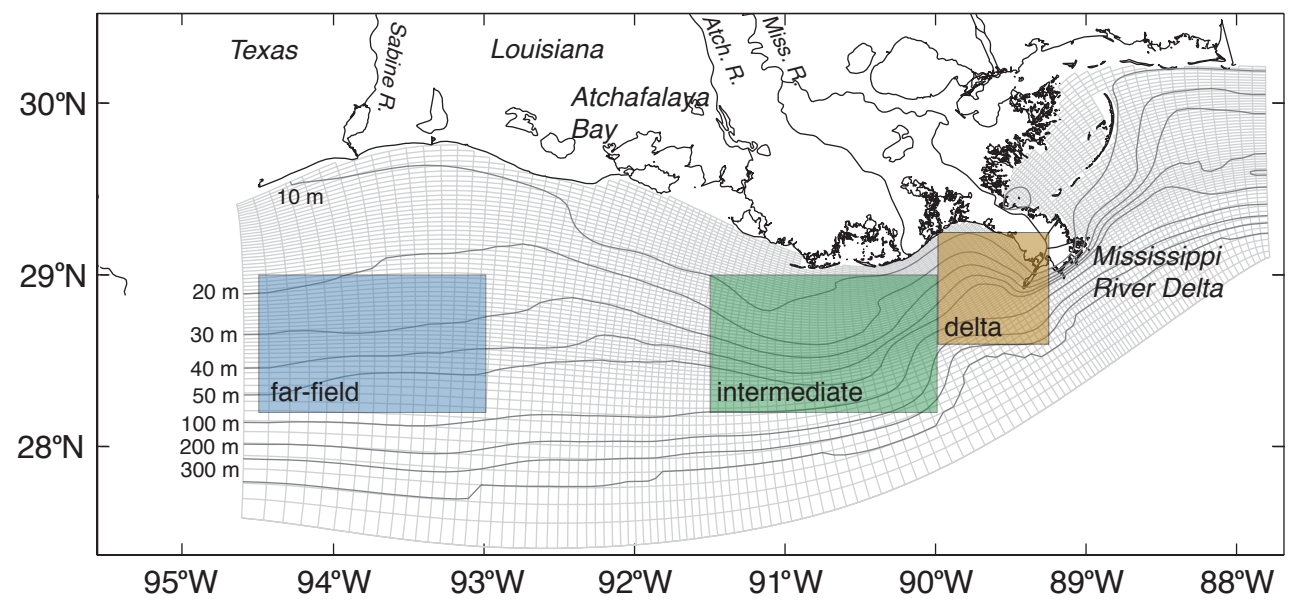

Fig. 1. Model domain and bathymetry. The colored boxes indicate areas used for averaging throughout the manuscript and are referred to as delta (brown), intermediate (green) and far-field (blue) region in the text.

in Hetland and DiMarco $(2008,2011)$. We provide a summary of the main features here. The model uses fourth-order horizontal advection of tracers, third-order upwind advection of momentum, conservative splines to calculate vertical gradients, and the Mellor and Yamada (1982) turbulence closure scheme for vertical mixing. The model is initialized on 1 January 1990 using an average winter profile of temperature and salinity calculated based on historical hydrographic data from the World Ocean Database (Boyer et al., 2006) and assumed to be horizontally uniform. We found a horizontally uniform initial condition to work well as most of the region is shallower than $50 \mathrm{~m}$ and completely homogenized during winter mixing. On the shelf, horizontal salinity gradients establish quickly (within a few weeks) after model start due to freshwater input from the Atchafalaya and Mississippi Rivers. The temperature and salinity boundary conditions use an adaptive nudging technique (Marchesiello et al., 2001) where tracers are relaxed to the horizontally uniform monthly climatology throughout the integration with a timescale of 10 days for outgoing information and 1 day for incoming information. The western boundary (downcoast, in the direction of Kelvin wave propagation), however, uses nogradient conditions for three-dimensional velocity and tracer information. This allows information to leave the domain with little impedance. At the other open boundaries, radiation conditions are used for the three-dimensional velocities and tracers. A Flather (1976) condition with no mean barotropic background flow is used for the two-dimensional velocities and free surface at all open boundaries.

Our model is forced with spatially uniform but temporally varying 3-hourly winds from the BURL 1 C-MAN weather station at $28^{\circ} 54^{\prime} \mathrm{N}, 89^{\circ} 25^{\prime} \mathrm{W}$ near the major pass of the Mississippi delta. Given the spatial scales of the local wind field (Wang et al., 1998), spatially uniform wind forcing is appropriate for our model domain. Data gaps were filled using neighboring buoys (first station 42040 located at $29^{\circ} 12^{\prime} \mathrm{N}$ $88^{\circ} 12^{\prime} \mathrm{W}$, then station 42007 located at $30^{\circ} 5^{\prime} \mathrm{N} 88^{\circ} 46^{\prime} \mathrm{W}$ ). We specified surface heat and freshwater fluxes using the climatological fields of da Silva et al. (1994a,b), and freshwater inputs from the Mississippi and Atchafalaya Rivers using daily measurements of transport by the US Army Corps of Engineers at Tabert Landing and Simmesport, respectively. We did not include tides, as they are known to be small in this region (DiMarco and Reid, 1998).

The physical model realistically captures the two distinct modes of circulation over the Texas-Louisiana shelf, namely the mean offshore flow during upwelling favorable winds in summer and the mean westward (downcoast) flow during downwelling favorable winds for the rest of the year, as described in Hetland and DiMarco (2008). Hetland and DiMarco (2011) assess the hydrodynamic model skill in reproducing moored current observations, and temperature and salinity distributions based on hydrographic surveys of water masses over the shelf for the periods from 1992 to 1994 and 2004 to 2005 . They defined skill as

skill $=1-\frac{\sum_{i=1}^{N}\left(m_{i}-o_{i}\right)^{2}}{\sum_{i=1}^{N}\left(c_{i}-o_{i}\right)^{2}}$

where $o_{i}$ are $N$ observations of the property in question, $m_{i}$ are the corresponding simulated values, and $c_{i}$ are the climatological values. Thus, a skill of zero means that the model error variance has the same magnitude as the variance in the observations relative to the climatology. A positive skill means that the model is a better predictor of the observed ocean state than the climatology. The model is able to reproduce observed salinity fields with a positive skill in all but one of sixteen hydrographic cruises; the mean skill for all cruises is 0.46 . The model skill at reproducing currents is essentially zero, but the model does successfully reproduce the mean flow speed and direction as well as the variance 
of the currents. These analyses suggest that the model is able to reproduce the large-scale structure of the Mississippi/Atchafalaya River plume over the Texas-Louisiana shelf. However, there also exists an energetic small-scale eddy field, which the model is only able to reproduce in terms of eddy variance, but not in detail. DiMarco et al. (2010) describe observations of small-scale, energetic features with spatial scales of $20-50 \mathrm{~km}$.

\subsection{Biological model}

The biological component of our model uses the nitrogen cycle model described in Fennel et al. (2006, 2008). The model is a relatively simple representation of biological nitrogen cycling processes in the water column. It includes seven state variables: two species of dissolved inorganic nitrogen (nitrate, $\mathrm{NO}_{3}$, and ammonium, $\mathrm{NH}_{4}$ ), one functional phytoplankton group, Phy, chlorophyll as a separate state variable, $\mathrm{Chl}$, to allow for photoacclimation, one functional zooplankton group, Zoo, and two pools of detritus representing large, fast-sinking particles, LDet, and suspended, small particles, SDet (see Fig. 2). The main processes are

1. temperature, light- and nutrient-dependent phytoplankton growth with ammonium inhibition of nitrate uptake,

2. zooplankton grazing represented by a Holling-type III parameterization,

3. aggregation of phytoplankton and small detritus to fast sinking large detritus,

4. photoacclimation (i.e. a variable ratio between phytoplankton and chlorophyll),

5. linear rates of phytoplankton mortality, zooplankton basal metabolism, and detritus remineralization,

6. a second order zooplankton mortality,

7. light-dependent nitrification (i.e. oxidation of ammonium to nitrate), and

8. vertical sinking of phytoplankton and detritus.

Here we only give the parameterizations for the first three processes. For other details on model justification, equations and parameters we refer the reader to Fennel et al. (2006, 2008). Similar to the model of Green et al. (2008) for the Texas-Louisiana shelf, our model does not explicitly include phosphate limitation as nitrogen is considered the dominant limiting nutrient.

The phytoplankton growth rate $\mu$ depends on temperature $T$ through the maximum growth rate $\mu_{\max }=\mu_{\max }(T)=$ $\mu_{0} 1.066^{T}$ (Eppley, 1972) with $\mu_{0}=0.69 \mathrm{~d}^{-1}$, on the photosynthetically active radiation $I$ and on the nutrient concentrations $\mathrm{NO}_{3}$ and $\mathrm{NH}_{4}$ according to

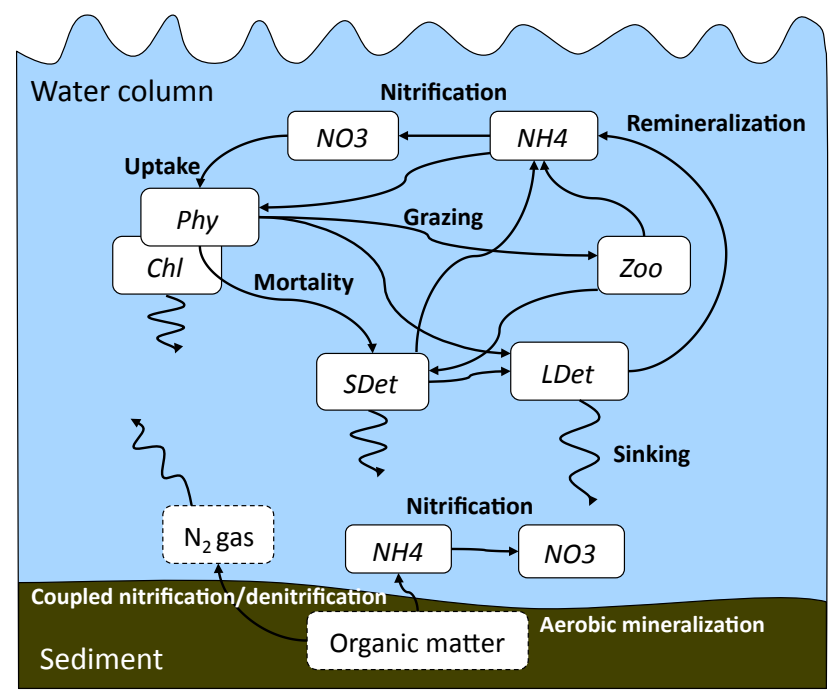

Fig. 2. Schematic of the biological model. State variables are shown in solid boxes. Variables that are not explicitly included are indicated by dashed boxes.

$\mu=\mu_{\max } f(I)\left(L_{\mathrm{NO}_{3}}+L_{\mathrm{NH}_{4}}\right)$

where

$L_{\mathrm{NO}_{3}}=\frac{\mathrm{NO}_{3}}{k_{\mathrm{NO}_{3}}+\mathrm{NO}_{3}} \frac{1}{1+\mathrm{NH}_{4} / k_{\mathrm{NH}_{4}}}$

and

$L_{\mathrm{NH}_{4}}=\frac{\mathrm{NH}_{4}}{k_{\mathrm{NH}_{4}}+\mathrm{NH}_{4}}$

with $k_{\mathrm{NO}_{3}}=k_{\mathrm{NH}_{4}}=0.5 \mathrm{mmol} \mathrm{N} \mathrm{m}{ }^{-3}$. The photosynthetically available light $I$ is exponentially decreasing with depth (see Eq. 7 below). The function $f(I)$ represents the photosynthesis-irradiance relationship (Evans and Parslow, 1985)

$f(I)=\frac{\alpha I}{\sqrt{\mu_{\max }^{2}+\alpha^{2} I^{2}}}$

where $\alpha=0.025\left(\mathrm{~W} \mathrm{~m}^{-2}\right)^{-1} \mathrm{~d}^{-1}$.

The phytoplankton loss due to macrozooplankton grazing is $g$ Zoo, where the grazing rate $g$ is represented by

$g=g_{\max } \frac{\mathrm{Phy}^{2}}{k_{\mathrm{P}}+\mathrm{Phy}^{2}}$

with a maximum grazing rate $g_{\max }=$ $\left.0.6(\mathrm{mmol} \mathrm{N} \mathrm{m})^{-3}\right)^{-1} \mathrm{~d}^{-1}$ and a half-saturation concentration for phytoplankton ingestion of $k_{\mathrm{p}}=2\left(\mathrm{mmol} \mathrm{N} \mathrm{m}^{-3}\right)^{2}$.

A first order mortality loss $m_{\mathrm{pPhy}}$ is included and represents the phytoplankton losses due to grazing by microzooplankton, which grow at similar rates as phytoplankton. The first order mortality rate $m_{\mathrm{P}}$ is $0.15 \mathrm{~d}^{-1}$. 
The phytoplankton loss due to aggregation of phytoplankton and small detritus is parameterized as $\tau$ (SDet + Phy)Phy and enters the pool of fast-sinking large detritus LDet. The aggregation parameter $\tau$ is $0.01\left(\mathrm{mmol} \mathrm{N} \mathrm{m}^{-3}\right)^{-1} \mathrm{~d}^{-1}$.

The representation of nitrogen cycling in the water column in our model is similar to other coupled models (e.g., Oschlies, 2002; Gruber et al., 2006), however, the model's treatment of sediment remineralization, which is critical for model application to continental shelf regions, is unusual. The model uses an empirical parameterization of sediment denitrification. Specifically, organic matter that reaches the sediment is remineralized in fixed proportions through aerobic and anaerobic remineralization. The fractions are determined using the linear relationship between sediment denitrification and oxygen consumption that Seitzinger and Giblin (1996, their Fig. 1) calculated for a compilation of published measurements (note that their relationship includes production of $\mathrm{N}_{2}$ gas through anammox; the term denitrification is used here to denote canonical denitrification following Devol (2008) and includes all processes that produce $\mathrm{N}_{2}$ gas). This empirical relationship was based on 50 data points. Fennel et al. (2009) compiled a larger data set including 648 data points across a range of aquatic environments, including from the coastal Gulf of Mexico, and reevaluated the linear regression. This new relationship deviates little from the previously published one, although the coefficient of determination for the larger data set is smaller than that of Seitzinger and Giblin (1996). Using the linear relationship between sediment oxygen consumption and denitrification, the stoichiometries for aerobic remineralization, denitrification and nitrification, and the assumptions that organic matter is remineralized instantaneously and that denitrification occurs through coupled nitrification-denitrification only, the fraction of remineralization that occurs through denitrification can be calculated. Essentially one assumes that sediment oxygen consumption results from aerobic remineralization and nitrification only. The details of this calculation are given in Fennel et al. (2006) and are not repeated here for the sake of brevity.

In combination with the freshwater discharge described above, the model receives inorganic and organic nutrients. Specifically nitrate, ammonium and particulate nitrogen fluxes (the latter is assumed to enter the pool of small detritus in the model) are specified (Fig. 3) based on monthly nutrient flux estimates from the US Geological Survey (Aulenbach et al., 2007). Particulate organic nitrogen fluxes are determined as the difference between total Kjeldahl nitrogen and ammonium.

In order to account for light attenuation in the river plume due to colored dissolved organic matter and suspended terrigenous sediments we introduced a salinity-dependent attenuation term in the calculation of the photosynthetically active radiation $I$ at depth $z$ as follows
$I(z)=I_{0} \cdot \operatorname{par} \cdot e^{-z K-z K_{\mathrm{salt}}-K_{\mathrm{chl}} \int_{0}^{z} \operatorname{Chl}(\zeta) d \zeta}$,

where $I_{0}$ is the incoming light just below the sea surface, par is the fraction of light that is available for photosynthesis, and $K$ and $K_{\mathrm{chl}}$ are the light attenuation coefficients for water and chlorophyll, respectively. The salinity-dependent attenuation is $K_{\text {salt }}=\max (-0.024 S+0.89,0)$ where $S$ is salinity.

Here, we present a $15-y r$ simulation starting on 1 January 1990 and ending on 31 December 2004. The biological variables $\mathrm{NH}_{4}$, Phy, Chl, Zoo, SDet and LDet were initialized with small constant values. $\mathrm{NO}_{3}$ was initialized with a horizontally homogenous mean winter profile based on data from the World Ocean Database (Boyer et al., 2006). As with temperature and salinity, we found a horizontally uniform nitrate profile to work well for initialization as model spin-up time is short (a few weeks) and horizontal nitrate gradients establish quickly due to nitrogen inputs from the Mississippi and Atchafalaya Rivers. At the open boundaries climatological $\mathrm{NO}_{3}$ distributions were prescribed using measurements from the LATEX and NEGOM cruises (Nowlin Jr. et al., 1998; Jochens et al., 2002). All other biological state variables at the boundary are set to small positive values.

\section{Results}

Here we describe key features of the simulated biological variables, focusing primarily on nutrients and phytoplankton, and compare simulated variables and rates to available observations. We first compare simulated surface nitrate and chlorophyll distributions and vertically integrated rates of primary production to observations, then describe the climatological seasonal cycle of simulated nitrate, phytoplankton and zooplankton for three sub-regions of the model domain, which represent an ecological gradient, and then compare simulated phytoplankton growth, zooplankton grazing and organic matter sedimentation rates to observational estimates.

\subsection{Surface nitrate concentrations}

First we show simulated surface nitrate concentrations plotted over salinity and in comparison to observations by Sylvan et al. (2006) in order to illustrate typical patterns of this property; then we present a more quantitative comparison of surface nitrate with observations.

During spring, the observed surface nitrate distribution on the shelf is determined to first order by the dilution/mixing of high-nitrate fresh water and uptake of nitrate by phytoplankton, consistent with the observations described in Lohrenz et al. (1999). During May of 2001, which was a typical year in terms of freshwater discharge, the surface nitrate observations most closely resemble a conservative mixing relationship (Fig. 4, symbols in top panel). Low nitrate concentrations of $<3 \mathrm{mmol} \mathrm{N} \mathrm{m}^{-3}$ are restricted to high salinities 

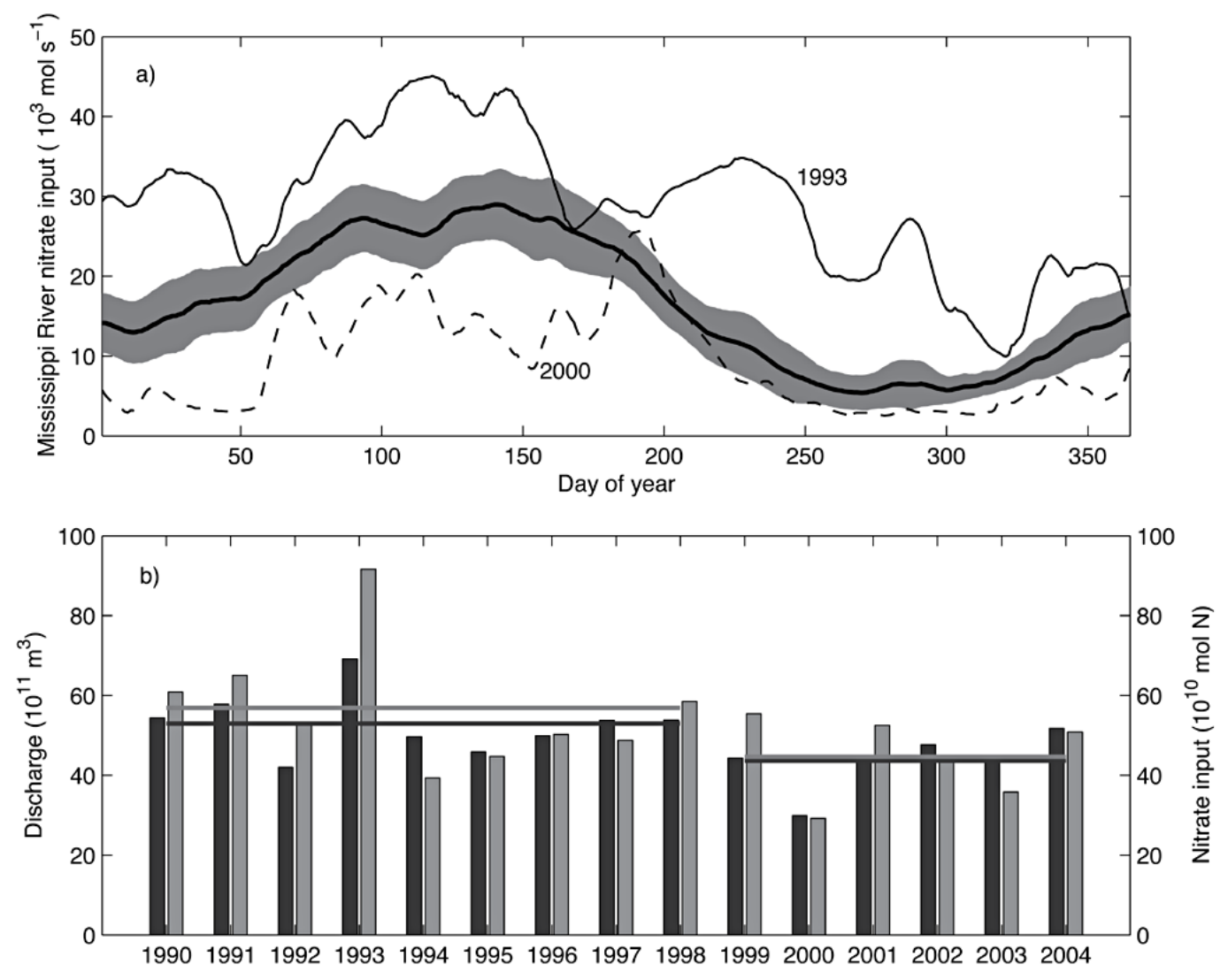

Fig. 3. (a) Climatological daily nitrate input from the Mississippi River (thick black line) and one standard deviation (gray area) for the period from 1990 to 2004. The daily nitrate input is also shown for the years of highest (1993, solid black line) and lowest (2000, dashed line) discharge. (b) Annual means of Mississippi River freshwater discharge (dark gray bars) and nitrate input (light gray bars). Mean freshwater discharge and nitrate input was lower for the years 1999 to 2004 with an average of $4.4 \times 10^{11} \mathrm{~m}^{3} \mathrm{yr}^{-1} \mathrm{and}^{4.5} \times 10^{10} \mathrm{molN}^{-1} \mathrm{yr}^{-1}$, respectively, than during the years 1990 to 1998 with $5.3 \times 10^{11} \mathrm{~m}^{3} \mathrm{yr}^{-1}$ and $5.7 \times 10^{10} \mathrm{~mol} \mathrm{~N}^{-1} \mathrm{yr}^{-1}$. Average annual discharges for both periods are shown as solid horizontal lines.

(>32) in May. Over the course of the summer, surface nitrate is drawn down at intermediate salinities and generally more variable. By September of 2001 all samples at intermediate salinities have low nitrate concentrations (Fig. 4, symbols in bottom panel). The simulated nitrate patterns are similar to the observations in terms of their monthly evolution. As seen in the observations, the simulated surface nitrate concentrations resemble a conservative mixing relationship most closely in May, and the different river end member concentrations from the Mississippi and Atchafalaya Rivers are clearly distinguishable (Fig. 4, top panel). Over the course of the summer, nitrate is drawn down at intermediate salinities, and consistently low by September.

For a more quantitative comparison we obtained all available surface nitrate observations for our study region from the World Ocean Database (Boyer et al., 2006) (the majority of the additional data is from LUMCON's hypoxia monitoring program; see, for example, Rabalais et al., 2002). We binned all surface nitrate data that fall into the delta and intermediate regions (defined in Fig. 1) by month (no data were available for the far-field region), and show their median, 25th and 75th percentiles, and minimum and maximum values over time in Fig. 5 (as black dots, and thick and thin vertical lines, respectively). Also shown are the model-simulated range between minimum and maximum (light gray), range between the 25th and 75th percentiles (darker gray) and median (thick line) for all three regions. The simulated and observed medians agree very well with the exception of January 2001 when the observations are atypically high in the intermediate region. For the months where more than 20 observations are available the range between minimum and maximum values agrees well with the simulation also (in months with fewer observations the nitrate distribution within the subregions is likely not sampled adequately and a comparison of the ranges is not meaningful). Figure 5 also illustrates that surface nitrate concentrations in the far-field region are very small, with a median typically below $0.2 \mathrm{mmol} \mathrm{N} \mathrm{m}^{-3}$ (the median reaches $0.5 \mathrm{mmol} \mathrm{N} \mathrm{m}^{-3}$ only briefly once during 1999 and once during 2003). 

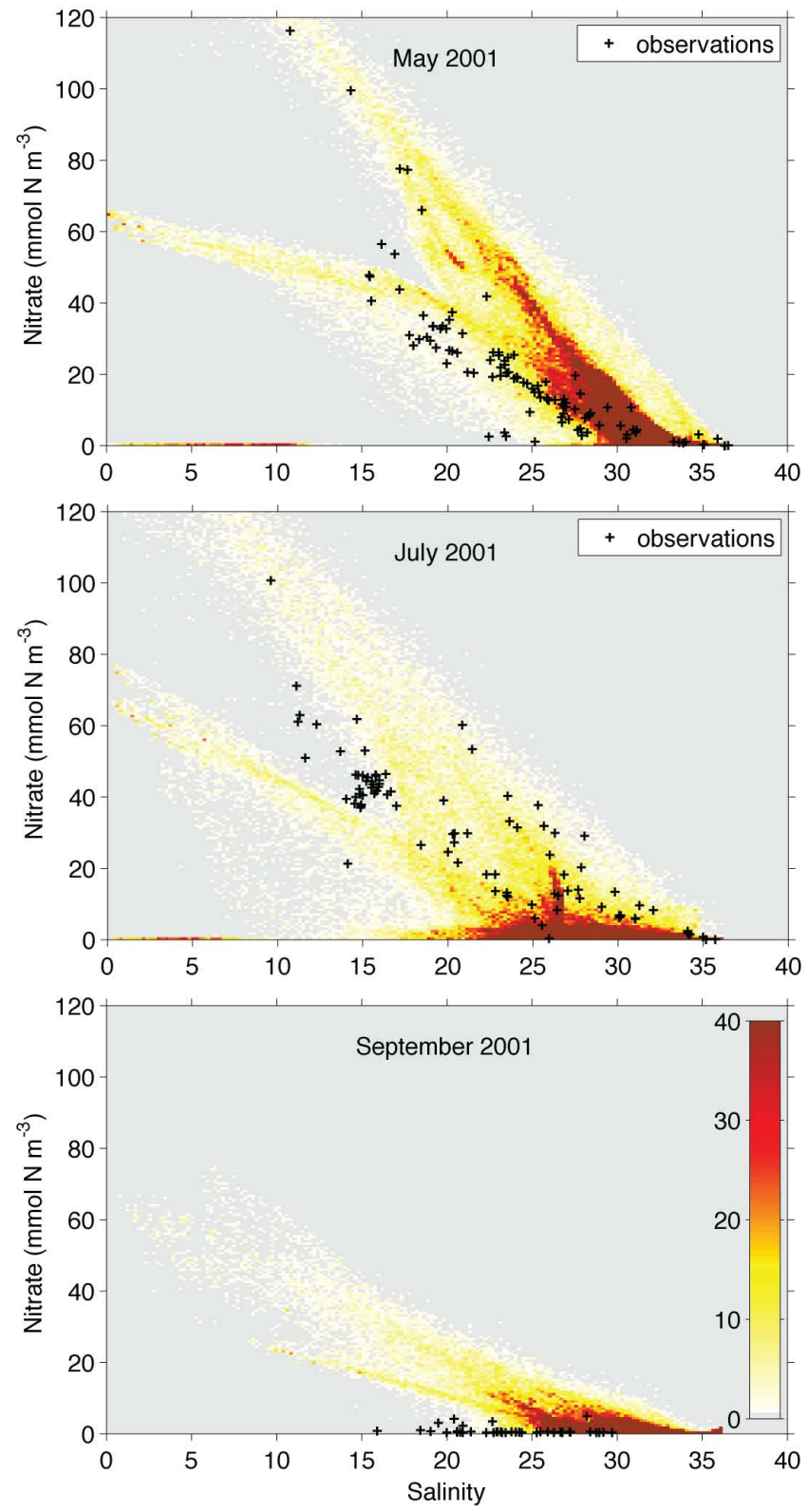

Fig. 4. Simulated surface nitrate concentrations are shown over salinity in form of a 2-dimensional histogram. All surface cells in the model domain are included. Color indicates the number of simulated nitrate-salinity-pairs per bin (see color scale in bottom right panel). Symbols represent surface nitrate observations for the same months.

\subsection{Surface chlorophyll and primary production}

We now compare the simulated surface chlorophyll to observations derived from the SeaWiFS satellite. First we show the spatial distribution of monthly means from 1998 to 2004 (i.e. when the simulation period overlaps with the SeaWiFS period) in Fig. 6. Chlorophyll concentrations are observed to be highest in the freshwater plumes $\left(>30 \mathrm{mg} \mathrm{m}^{-3}\right)$ and show a generally decreasing tendency from high concentrations near shore ( 1 to $10 \mathrm{mg} \mathrm{m}^{-3}$ ) to values $<1 \mathrm{mg} \mathrm{m}^{-3}$ near the shelf break (Fig. 6).

More quantitative comparisons for the subregions defined above are presented in Figs. 7, 8 and 9. Since only the second part of our simulation overlaps with the SeaWiFS observations, we split the comparison into two periods: (1) January 1990 to December 1997 for which we use the monthly SeaWiFS climatology (Fig. 7), and (2) January 1998 to December 2004 for which we use monthly SeaWiFS means for the specific year (Figs. 8 and 9). In general chlorophyll concentrations are lowest in winter, increase in spring, remain high throughout summer, and decrease in early fall (Fig. 6). For the first period shown in Fig. 7, the model tends to overestimate the observations in all three regions, which is not surprising as nitrogen loads were markedly higher from 1990 to 1998 compared to most of the SeaWiFS data period from 1999 to 2004 (see Fig. 3). In the delta region the model reproduces the climatology best in the years 1992 and 1994, which were similar in terms of freshwater discharge and nutrient input to the SeaWiFS years. The largest summer chlorophyll concentrations are predicted for 1993 (the year with highest discharge and nitrogen load). For the intermediate region, the range and temporal evolution of chlorophyll agrees well with the climatology, in particular for the years 1992 and 1996 to 1998. In 1993 the model predicts higher than average chlorophyll concentrations as one would expect given the disproportionate nitrogen load that year. Also, the occasionally elevated chlorophyll values in summer are likely due to the larger nitrogen loads, especially for the first half of the simulation period. For the far-field region the modelsimulated values agree well with the climatology from 1995 through 1998, i.e. the years when Mississippi River nitrogen loads were closer to loads observed during our SeaWiFS data period, while concentrations are above the climatology from 1990 to 1994.

For the period where the simulation overlaps with the SeaWiFS record (1998 to 2004; shown in Fig. 8) the amplitude of simulated chlorophyll agrees much better with the observations in all three regions. In the delta region, the model overestimates chlorophyll in summer of 1998, but reproduces observed chlorophyll closely in the summers of 1999 to 2004. Chlorophyll accumulation in spring is delayed in the model compared with the observations, as was apparent also in the climatological comparison in Fig. 7. In the intermediate region, the model is tracking seasonal and interannual variations well without any systematic differences (Fig. 8), although the model occasionally over- and underestimates the observations, e.g. in February 1999, June 2002 and March 2003. In the far-field region the simulated chlorophyll is close to observations (Fig. 8) and consistently lower than during the years with higher discharge from 1990 to 1994 (see Fig. 7).

The observed monthly mean chlorophylls and their standard deviations are shown over their corresponding 


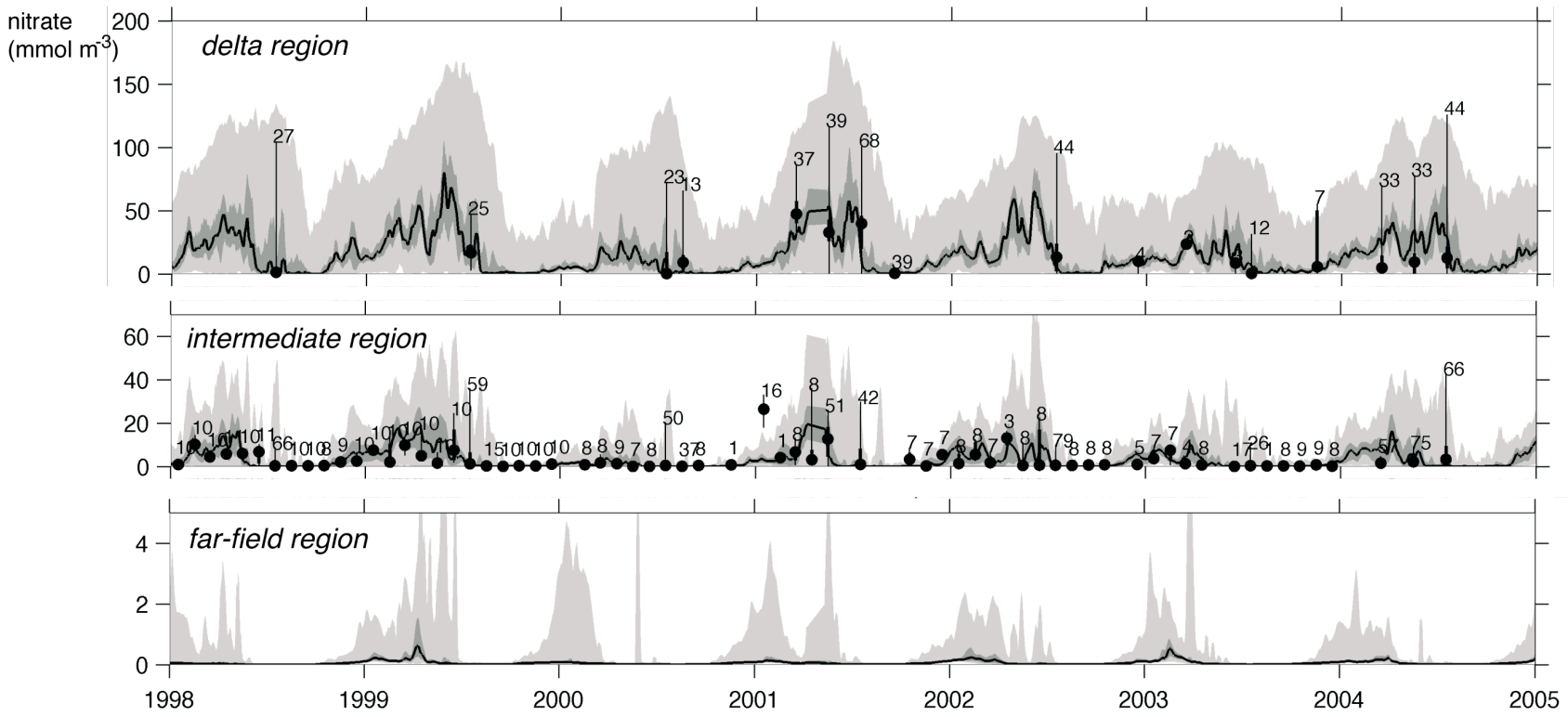

Fig. 5. Median (thick line), range between 25th and 75th percentiles (dark gray) and range between minimum and maximum simulated surface nitrate in the delta, intermediate and far-field regions (defined in Fig. 1) and corresponding median (dots), range between 25th and 75th percentiles (thick vertical lines) and range between minimum and maximum values (thin vertical lines) of monthly binned observations. The number of observations in each monthly bin is shown near each maximum value.

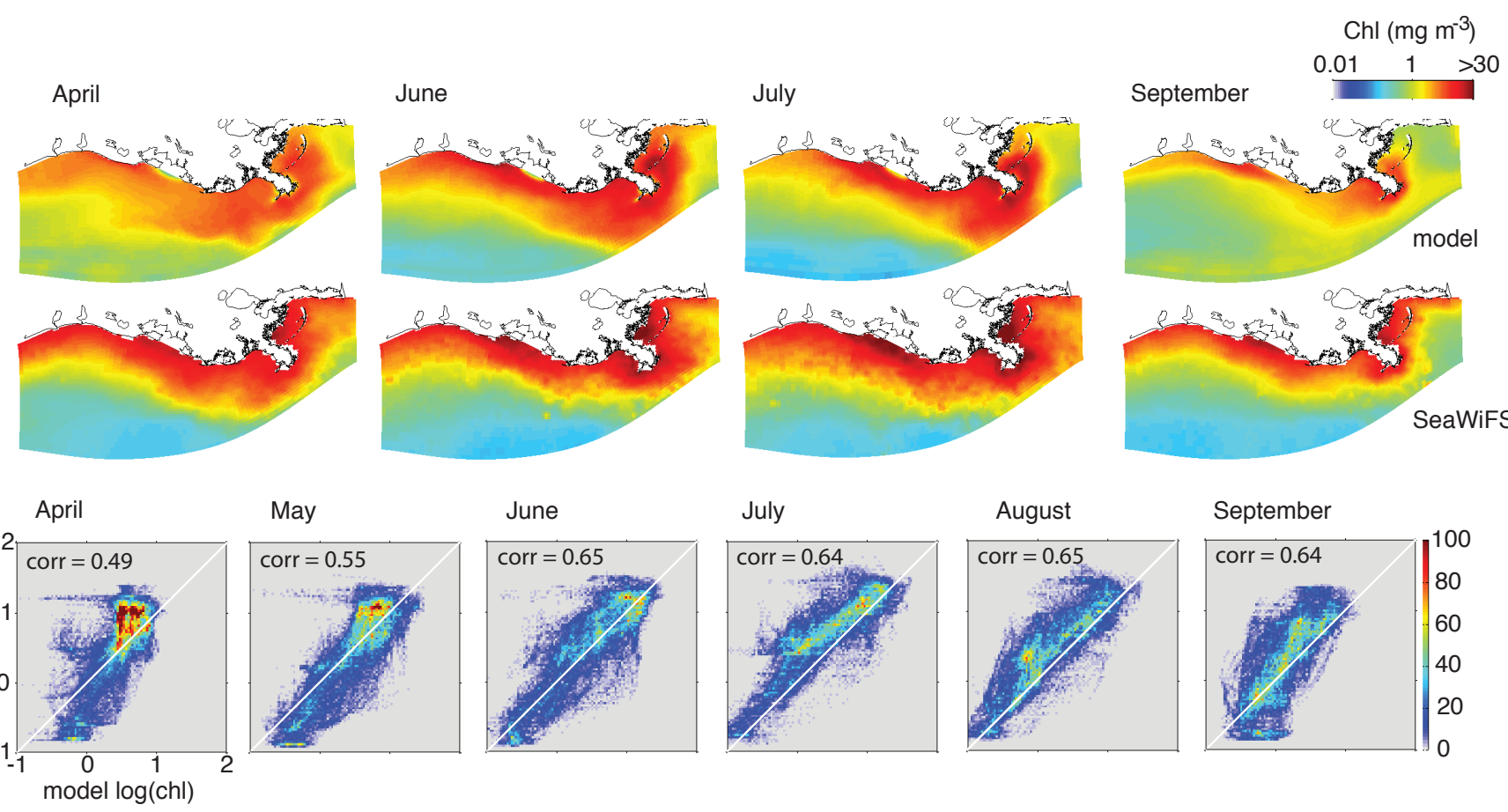

Fig. 6. Monthly climatology of simulated surface chlorophyll for the years 1998 to 2004 (top row) and surface chlorophyll from the SeaWiFS satellite for the same period (row below) for April, June, July and September. 2-dimensional histograms of SeaWiFS over model chlorophyll from April through September and their correlation are shown in the bottom row. The 1-to-1 line is shown in white. Color indicates the number of simulated and observed chlorophyll pairs per bin (see color scale at the bottom right). 


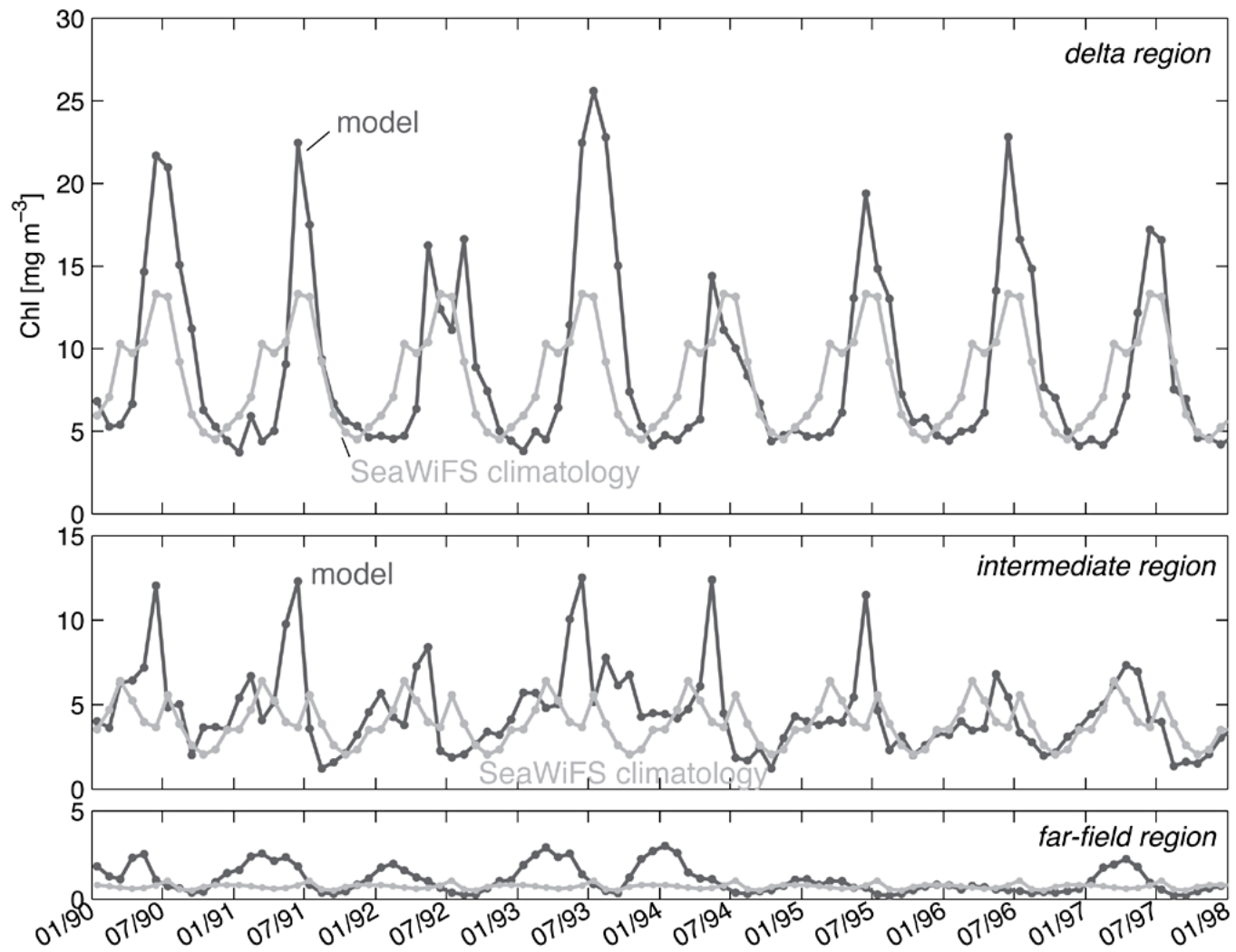

Fig. 7. Monthly mean surface chlorophyll concentrations for January 1990 to December 1997 in comparison with the monthly SeaWiFS climatology, both averaged over the delta, intermediate and far-field regions.

simulated values in Fig. 9. The corresponding coefficient of determination is $64 \%$, which is encouraging. It should be noted here that no systematic parameter tuning or formal parameter optimization was performed.

We also compared simulated rates of primary production ( $\mu$ Phy), averaged for the delta and intermediate regions, to the observations of Lohrenz et al. (1997) (Fig. 10). The simulated rates were calculated assuming a constant $\mathrm{C}$-to-N ratio of 106:16 (as is commonly done in nitrogen-based models). Observed rates range from typically $\sim 1 \mathrm{~g} \mathrm{C} \mathrm{m}^{-2} \mathrm{~d}^{-1}$ in fall or winter to maximum values between 3 and $4 \mathrm{~g} \mathrm{C} \mathrm{m}^{-2} \mathrm{~d}^{-1}$ during spring and summer, but are highly variable, as indicated by the large standard deviations associated with some values and the large differences in observations made only a few days apart (e.g. in spring of 1993). The simulated rates agree with the observations in terms of magnitude and temporal patterns; they agree especially well in 1990 and 1992. The small observed primary production value for the delta region in early 1991 seems unrealistically low (it is much smaller than primary production in the intermediate region) and is likely not an adequate representation of the mean primary production for the delta region.

\subsection{Seasonal cycle of nitrate, phytoplankton and zooplankton}

In the following, we will discuss model-simulated cycles of climatological monthly means of properties (e.g. nitrate and phytoplankton concentrations) and rates (e.g. growth and grazing rates) which were averaged vertically over the mixed layer and horizontally over the three regions shown in Fig. 1. The mixed layer depth was defined here as the shallowest water depth at which temperature is at least $0.5^{\circ} \mathrm{C}$ below the surface temperature. Climatological monthly mean mixed layer depths and surface salinities are shown in Fig. 11. In all three regions, the average mixed layer depth shoals to about 10 to $15 \mathrm{~m}$ in summer from between 30 to $40 \mathrm{~m}$ in winter. Mean surface salinity differs systematically between the regions with lowest salinities and the most pronounced seasonal cycle in the delta region, and highest salinities and the weakest seasonal cycle in the far-field, as one would expect.

The delta, intermediate and far-field regions differ also markedly in terms of nutrient supply and evolution of phytoplankton and zooplankton (Fig. 12). In the delta region, average nitrate is near or above $8 \mathrm{mmol} \mathrm{N} \mathrm{m}^{-3}$ all year (i.e. well above concentrations near or below $1 \mathrm{mmol} \mathrm{N} \mathrm{m}^{-3}$ considered limiting to phytoplankton). A reduction in nitrate occurs 


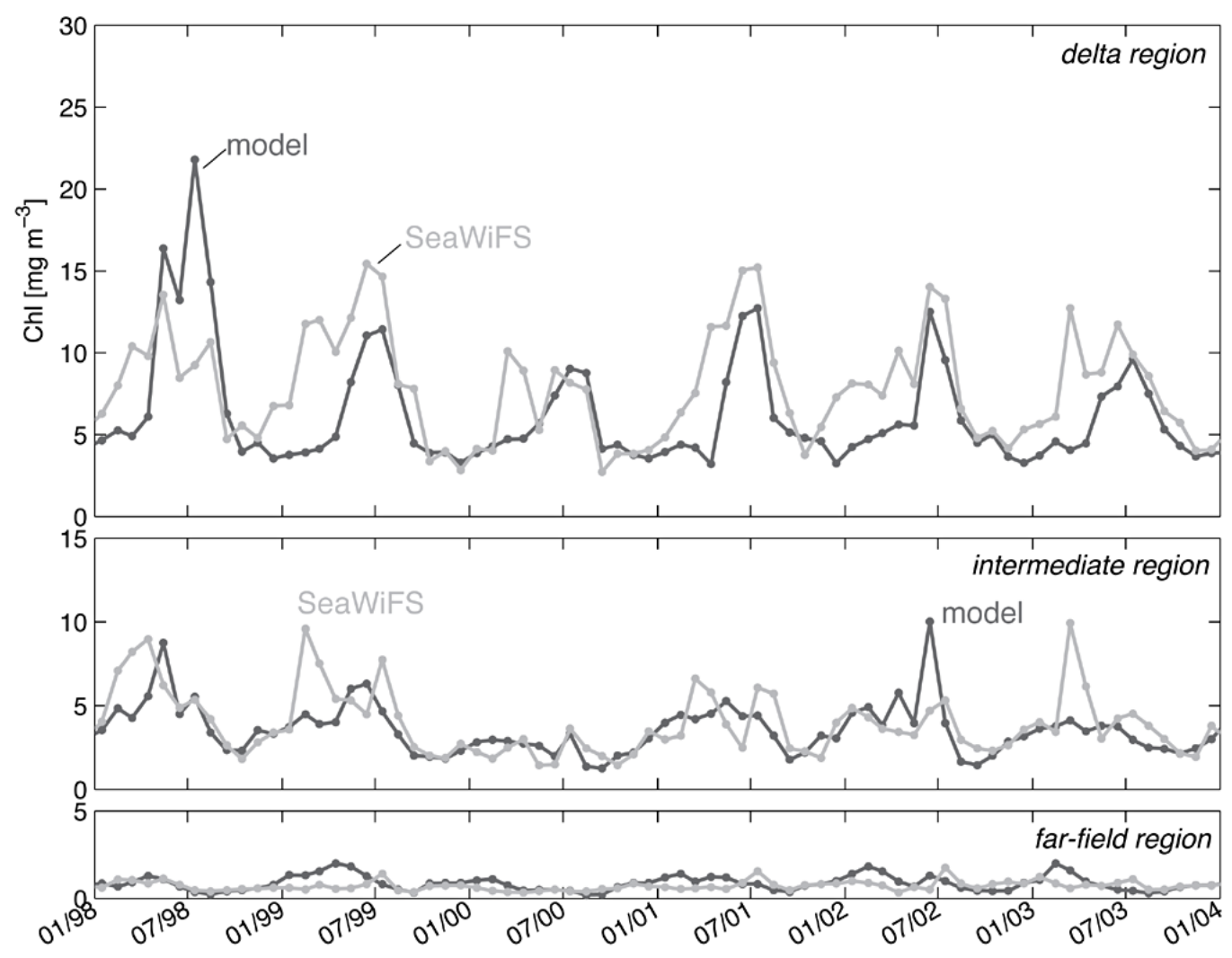

Fig. 8. Monthly mean surface chlorophyll concentrations in comparison with the monthly SeaWiFS means for January 1998 to December 2004, both averaged over the delta, intermediate and far-field regions.

from April to October (by $\sim 25 \mathrm{mmol} \mathrm{N} \mathrm{m}^{-3}$ ) through dilution (i.e. export of nitrate across the delta region's boundary) and phytoplankton uptake, and nitrate is replenished again during the other months of the year through river input and, to a lesser degree, remineralization. Average nitrate concentrations in the intermediate region are near $10 \mathrm{mmol} \mathrm{N} \mathrm{m}^{-3}$ during winter and early spring but drop to limiting concentrations between April and July, and remain low for the following 4 to 5 months. In the far-field region, average mixed layer nitrate is always at limiting concentrations.

Average mixed layer phytoplankton biomasses in the delta and intermediate regions are near $2 \mathrm{mmol} \mathrm{N} \mathrm{m}^{-3}$ from December to March and begin to increase and diverge in April, reaching maximum concentrations of $7 \mathrm{mmol} \mathrm{N} \mathrm{m}^{-3}$ in the delta region in July and $3.5 \mathrm{mmol} \mathrm{N} \mathrm{m}^{-3}$ in the intermediate region (Fig. 12). In contrast, maximum zooplankton concentrations are very similar $\left(\sim 4 \mathrm{mmol} \mathrm{N} \mathrm{m}^{-3}\right.$ in June $)$ in the delta and intermediate regions and remain similar throughout the whole seasonal cycle. In the far-field region, average mixed layer phytoplankton biomass is almost stationary near $1 \mathrm{mmol} \mathrm{N} \mathrm{m}^{-3}$, while zooplankton biomass exhibits a seasonal cycle with increasing concentrations in spring. Here the phytoplankton standing stock is supported by recycled production. During spring and early summer, average mixed layer zooplankton biomass exceeds that of phytoplankton in the far-field region.

\subsection{Phytoplankton growth rates}

We calculated the mixed layer averages of the phytoplankton growth rate $\mu=\mu_{\max } f(I)\left(L_{\mathrm{NO}_{3}}+L_{\mathrm{NH}_{4}}\right)$ and plotted the climatological monthly means for the 15 -yr simulation period in Fig. 13a. The simulated growth rates in the three regions covary with minima between 0.2 and $0.4 \mathrm{~d}^{-1}$ in October and maxima between 1 and $1.4 \mathrm{~d}^{-1}$ in May, but are systematically higher in the intermediate region in spring and early summer (Fig. 13a). The simulated rates can be compared with the observed rates of Fahnenstiel et al. (1995), who reported taxon-specific growth rates of the dominant phytoplankton taxa for the delta and intermediate regions for March 1991 and July/August 1990. These observed growth rates varied considerably between taxa with lowest values of $<0.1 \mathrm{~d}^{-1}$ and maximum rates of $3 \mathrm{~d}^{-1}$. Since our model considers only one phytoplankton group, which represents the whole phytoplankton community, we compare the simulated rates with the observed mean and median growth rates of Fahnenstiel et al. (1995). In March 1991 the observed mean and median rates were 0.5 and $0.4 \mathrm{~d}^{-1}$, respectively, and agree 


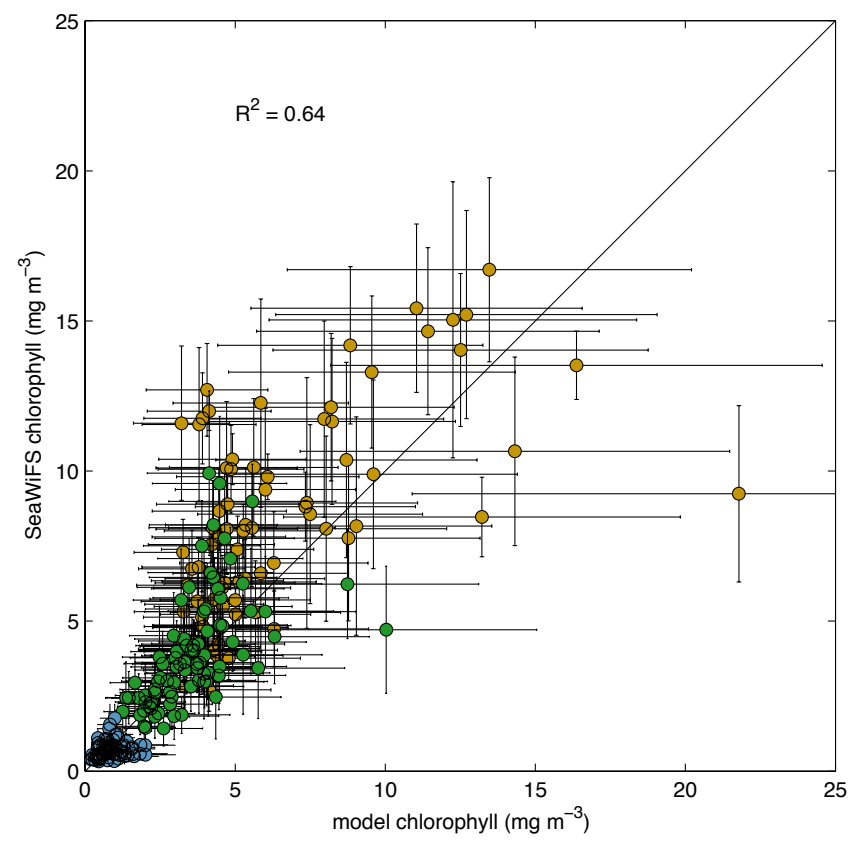

Fig. 9. Monthly mean SeaWiFS chlorophyll concentrations from January 1998 to December 2004 plotted over simulated surface chlorophyll; both averaged over the delta (brown dots), intermediate (green dots) and far-field (blue dots) regions. Errorbars indicate one standard deviation. The 1-to-1 line is shown as black line. Coefficient of determination, defined as $R^{2}=1-\frac{\mathrm{SS}_{\text {err }}}{\mathrm{SS}_{\mathrm{tot}}}$ with the total sum of squares $\mathrm{SS}_{\text {tot }}=\sum_{i}\left(o_{i}-\bar{o}\right)^{2}$, the residual sum of squares $\mathrm{SS}_{\mathrm{err}}=\sum_{i}\left(m_{i}-o_{i}\right)^{2}$, monthly mean observed values $o_{i}$, and monthly mean model values $m_{i}$, is given.

remarkably well with the model simulated growth rates of $0.5 \mathrm{~d}^{-1}$ for the delta region and $0.7 \mathrm{~d}^{-1}$ for the intermediate region for March 1991 (not shown). The observed mean and median growth rates for July/August 1990 were 1.3 and $1.0 \mathrm{~d}^{-1}$, which also agree very well with the simulated rates of $1.1 \mathrm{~d}^{-1}$ for July 1990 and $0.8 \mathrm{~d}^{-1}$ for August 1990 in the delta region (not shown).

\subsection{Zooplankton grazing and other loss terms}

The zooplankton variable in our model is assumed to primarily represent macrozooplankton such as copepods, which have lower growth rates than phytoplankton during bloom conditions and thus lag behind phytoplankton in spring. Microzooplankton, however, grow at similar rates as small phytoplankton and are thus able to respond to increasing phytoplankton concentrations without delay. These microzooplankton grazers are not represented explicitly in our model, however, the first order mortality loss of phytoplankton can be interpreted to represent the grazing loss of microzooplankton. This first order mortality loss (represented by $m_{\text {PPhy }}$ ) is largest in May, June and July in the delta region with mean values of $50-70 \mathrm{mg} \mathrm{C} \mathrm{m}^{-2} \mathrm{~d}^{-1}$, and smaller by about half in the intermediate region (Fig. 14e). The first order mortality loss is much smaller in the far-field region with summer rates of about $10 \mathrm{mg} \mathrm{C} \mathrm{m}^{-2} \mathrm{~d}^{-1}$.

The macrozooplankton grazing losses (represented by $g$ Zoo) are higher than the first order, microzooplankton grazing losses with mean values of about $120-150 \mathrm{mg} \mathrm{C} \mathrm{m}^{-2} \mathrm{~d}^{-1}$ in May and June in the delta and intermediate regions, and between $30-40 \mathrm{mg} \mathrm{C} \mathrm{m}^{-2} \mathrm{~d}^{-1}$ in the far-field region (Fig. 14a). These rates can be compared with the copepod grazing rates determined by Dagg (1995), who estimated daily ingestion rates of 537 and $92 \mathrm{mg} \mathrm{C} \mathrm{m}^{-2} \mathrm{~d}^{-1}$ at stations in the delta and intermediate regions, respectively, in September of 1991 , and 166 and $147 \mathrm{mg} \mathrm{C} \mathrm{m}^{-2} \mathrm{~d}^{-1}$ at the same stations in May of 1992. Both, the May 1992 rates and the September 1991 intermediate region rate, are similar to the model-simulated mean rates. The rate observed in the delta region in September 1991 (537 $\left.\mathrm{mg} \mathrm{C} \mathrm{m}^{-2} \mathrm{~d}^{-1}\right)$ is much higher than the model-simulated mean rate for the region, which may in part be due to averaging (the simulated daily rates reached values up to $320 \mathrm{mg} \mathrm{C} \mathrm{m}^{-2} \mathrm{~d}^{-1}$ ).

The simulated monthly mean aggregation rates (represented by $\tau($ SDet + Phy $)$, which are indicative of the sedimentation flux, range between 0.1 and $0.45 \mathrm{~d}^{-1}$ in the delta region and between 0.05 and $0.25 \mathrm{~d}^{-1}$ in the intermediate region (note that aggregation losses, i.e. $\tau$ (SDet + Phy)Phy, are given in Fig. 14c). Fahnenstiel et al. (1995) estimated taxonspecific sedimentation rates between $<0.001$ and $1.0 \mathrm{~d}^{-1}$ in the delta and intermediate region and found the largest sedimentation fluxes associated with diatoms. While these rates are not representative of the phytoplankton community and thus cannot be compared directly to the model-simulated rates it is worthwhile noting that the model-simulated rates are within the observed range. Aggregation loss has the most pronounced spatial dependence of all three biological loss terms. In the delta region, aggregation loss is similar in magnitude to the combined grazing and mortality losses. In the intermediate region, aggregation loss is similar to the first order mortality losses, but much smaller than the macrozooplankton grazing term. In the far region, aggregation loss makes up less than half of the first order mortality term and both are much smaller then macrozooplankton grazing.

\section{Discussion}

Our model simulation agrees with observed spatial and temporal patterns and distributions of surface nitrate, surface chlorophyll and primary production. Simulated rates of primary production, phytoplankton growth, and zooplankton grazing agree well with the corresponding observed rates. Thus, we feel that the simulations capture phytoplankton dynamics on the Texas-Louisiana shelf well enough to investigate the underlying drivers in the model and make inferences about processes in the natural system. First, we discuss which factors limit phytoplankton growth in the 


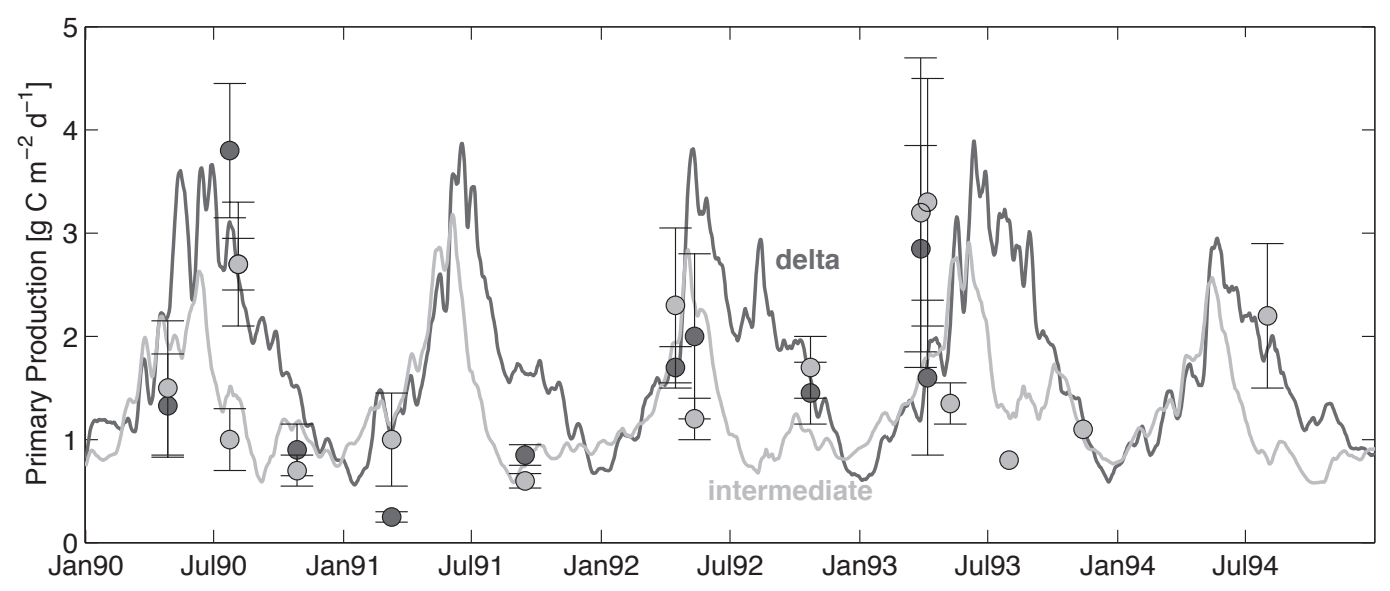

Fig. 10. Simulated primary production averaged for the delta and intermediate regions (solid lines) compared to measurements by Lohrenz et al. (1997) for the same regions (filled circles with errorbars represent mean and standard deviation). The dark and lights gray symbols and lines correspond to the delta and intermediate regions, respectively.

delta, intermediate and far-field regions and contrast the relative importance of different phytoplankton losses in these regions. We then examine relationships between monthly mean primary production in the delta region and Mississippi River nitrate load in order to elucidate why primary production in this region is correlated with nitrate load even though phytoplankton growth is not limited by nitrate.

\subsection{Factors controlling plankton growth and accumulation of biomass}

In order to investigate which factors limit phytoplankton growth in the three regions, we calculated the mixed layer mean light-limitation term $f(I)$ and show its climatological monthly means for the 15-yr simulation period in Fig. 13b. Small values of $f(I)$ indicate light-limitation, while values near 1 correspond to no light-limitation. We also calculated the mixed layer mean values of the nutrient-limitation term $L_{\mathrm{TOT}}=L_{\mathrm{NO}_{3}}+L_{\mathrm{NH}_{4}}$ and show its climatological monthly means in Fig. 13c. Again, values of $L_{\mathrm{TOT}}$ near 1 correspond to no nutrient-limitation, while small values indicate nutrient-limitation.

As expected, light-limitation is strongest in the delta and weakest in the far-field region. There is a pronounced seasonal cycle to the light-limitation term that is coherent in all three regions with strongest light-limitation in late fall and winter and lowest light-limitation in early summer. Except for fall, where light-limitation in the intermediate and farfield regions is of similar magnitude, there is always a pronounced spatial gradient with strongest light-limitation in the delta region and weaker light-limitation in the intermediate and far-field regions. The patterns of nutrient limitation are opposite in many respects. There is essentially no nutrient-limitation in the delta region; nutrient-limitation increases toward the intermediate and far-field regions. In all three regions nutrient-limitation is more pronounced in the fall and weakest in the spring. The ratio of $f(I)$ and $L_{\mathrm{TOT}}$ (Fig. 13d) can be interpreted as a measure of the relative importance of light- versus nutrient-limitation (small values correspond to light-limitation) and illustrates that the delta region is strongly light-limited all year, while the far-field region is strongly nutrient-limited in summer, and the intermediate region is midway between the two. Seasonal changes in this ratio are small in the delta region, and most pronounced in the far-field region where limitation by light becomes more important in winter. The phytoplankton growth rate is determined by the product of $f(I)$ and $L_{\mathrm{TOT}}$, which largely compensate for each other across the spatial gradient, and is modulated only by the temperature-dependent value of the maximum growth rate, which is very similar in all three regions and contributes to the pronounced seasonal cycle in phytoplankton growth rates (Fig. 13a).

The phytoplankton growth rate in the delta region is lower than in the intermediate region from October through July, yet, phytoplankton biomass and primary production are higher in the delta region (by a factor of 2 in July). It can be inferred that the spatial structure in phytoplankton loss terms contributes significantly to the regional differences in phytoplankton accumulation.

In the geographic regions considered here, phytoplankton can be lost by physical transport across the region boundaries and by biological losses (i.e. grazing-induced mortality, sinking). The sum of the climatological biological loss terms (described individually in Sect. 3.5 above; shown in Fig. 14d) varies between a minimum of $20-40 \mathrm{mg} \mathrm{C} \mathrm{m}^{-2} \mathrm{~d}^{-1}$ in winter in all three regions and markedly different maxima in early summer of 400,200 and $50 \mathrm{mg} \mathrm{C} \mathrm{m}^{-2} \mathrm{~d}^{-1}$ in the delta, intermediate and far-field regions, respectively (Fig. 14d). When comparing climatological primary production and the sum of biological losses (Fig. 14b and d) it is obvious that they follow a very similar pattern and have similar magnitudes. Accumulation of phytoplankton is determined by the imbalance 
Table 1. Linear correlation coefficients and $p$-levels for the delta region.

\begin{tabular}{lccl}
\hline Variables & Correlation & $p$-level & significant at $p<0.05 ?$ \\
\hline PP and DIN (Oct-Feb) & -0.46 & $<0.0001$ & yes (highly) \\
PP and DIN (Oct-Mar) & -0.18 & 0.1 & no \\
PP and DIN (Oct-Apr) & 0.35 & $<0.0002$ & yes (highly) \\
PP and DIN (Jun-Sep) & 0.64 & $<10^{-7}$ & yes (highly) \\
PP and DIN (May-Sep) & 0.52 & $<10^{-5}$ & yes (highly) \\
climatologies of PP and DIN (Jun-Sep) & 0.99 & 0.01 & yes \\
climatologies of PP and DIN (Jun-Oct) & 0.98 & 0.0036 & yes \\
anomalies of PP over DIN (Jun-Sep) & 0.31 & 0.018 & yes \\
anomalies of growth rate and DIN (Jun-Sep) & -0.30 & 0.029 & yes \\
anomalies of Chl and DIN (Jun-Sep) & 0.50 & $<10^{-5}$ & yes (highly) \\
& & & \\
PP and N load (Oct-Feb) & -0.42 & $<0.0001$ & yes (highly) \\
PP and N load (Oct-Mar) & -0.11 & 0.32 & no \\
PP and N load (Oct-Apr) & 0.33 & $<0.0006$ & yes (highly) \\
PP and N load (Jun-Sep) & 0.80 & $<10^{-13}$ & yes (highly) \\
PP and N load (May-Sep) & 0.68 & $<10^{-10}$ & yes (highly) \\
climatologies of PP and N load (Jun-Sep) & 1.00 & $<0.0001$ & yes (highly) \\
climatologies of PP and N load (Jun-Oct) & 0.99 & $<0.0001$ & yes (highly) \\
anomalies of PP over N load (Jun-Sep) & 0.58 & $<10^{-5}$ & yes (highly) \\
anomalies of growth rate and N load (Jun-Sep) & -0.12 & 0.37 & no \\
anomalies of phy and N load (Jun-Sep) & 0.77 & $<10^{-12}$ & yes (highly) \\
\hline
\end{tabular}

of production and losses, which is shown in Fig. 14f for primary production and biological losses (i.e. the difference between Fig. 14b and d).

In the delta region, there is a positive imbalance from April to July reaching a maximum of about $60 \mathrm{mg} \mathrm{C} \mathrm{m}^{-2} \mathrm{~d}^{-1}$ in June. In May and June this imbalance corresponds to about $10 \%$ of primary production, in other words, roughly $10 \%$ of primary production can accumulate while about $\sim 90 \%$ is lost to grazing, mortality and sinking. During the rest of the year the phytoplankton standing stock is in balance or declining (the imbalance between primary production and biological losses is near zero or negative).

In the intermediate region, the imbalance of primary production and biological losses is negative most of the year, approaching zero only in winter, despite the accumulation of phytoplankton in spring when it is doubling its standing stock compared to winter values (Fig. 12). We infer that advection and mixing of phytoplankton results in a net transport from the delta to the intermediate region supporting the accumulation of phytoplankton biomass in the latter. A similar picture emerges for the far-field region, where primary production and biological losses are in balance for most of the year, except during spring and early summer when biological losses exceed primary production, while the phytoplankton standing stock is increasing slightly. This indicates that physical transport of phytoplankton into the far-field region occurs at this time.
In summary, small mismatches between primary production and phytoplankton losses can explain the pronounced regional differences in phytoplankton standing stock and primary production that are observed to occur between the delta, intermediate and far-field region.

\subsection{Correlations between primary production and nutrients for the delta region}

Analysis of the limitation terms on phytoplankton growth (Fig. 13; previous section) indicates that phytoplankton growth in the delta region is not limited by nitrate in our model. This is also in agreement with observations by Lohrenz et al. (1999) that indicate phytoplankton is lightlimited in this region. Yet, a correlation between Mississippi nitrogen load and primary production has been shown to exist for this region by Lohrenz et al. (1997) and, more recently based on a larger data set, by Lehrter et al. (2009). The existence of this correlation is often interpreted as a bottom up effect of river nutrients directly stimulating primary production, which appears to be in contradiction with the observed lack of nutrient limitation. Our model simulation allows us to examine the nature of this relationship in more detail.

First, we examine the relationship between monthly mean primary production in the delta region and monthly $\mathrm{NO}_{3}$ load from the Mississippi over the 15-yr simulation period. Two distinct linear relationships with very different slopes exist (Fig. 15a). From October through March there is 

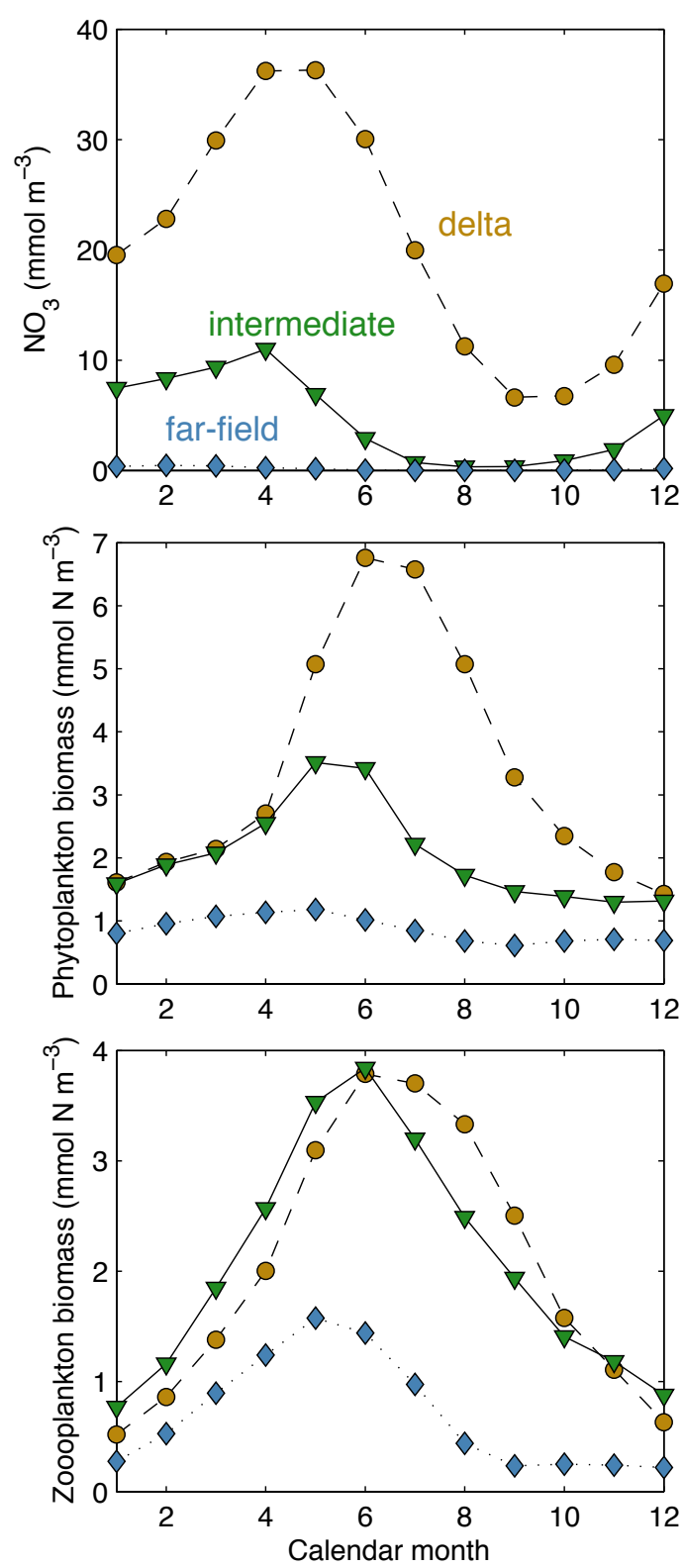

Fig. 11. Climatological monthly means of simulated mixed layer depth (top) and surface salinity (bottom) for the delta, intermediate and far-field regions (see Fig. 1).

a statistically significant linear relationship between monthly primary production and monthly $\mathrm{NO}_{3}$ load with a slightly negative slope. In other words, during this period primary production is essentially insensitive to $\mathrm{NO}_{3}$ load. From May through September a different and statistically significant relationship emerges with a positive slope. During this period, primary production is elevated when $\mathrm{NO}_{3}$ load and, by implication, surface DIN concentrations are high (Fig. 15a, the same pattern emerges when primary production is related to monthly mean DIN concentrations in the delta region instead of $\mathrm{NO}_{3}$ load; see Table 1). In other words, the system shifts
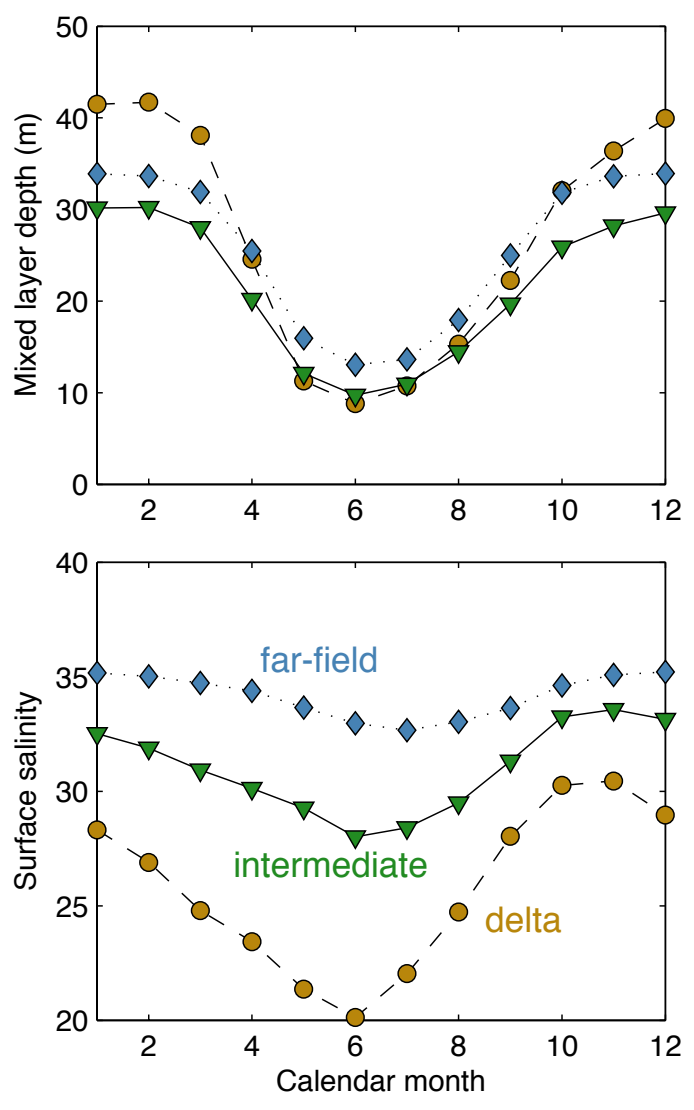

Fig. 12. Climatological monthly means of simulated mixed layer nitrate (top), phytoplankton (middle) and zooplankton (bottom) biomasses for the delta, intermediate and far-field regions (see Fig. 1).

from a phase of insensitivity to $\mathrm{NO}_{3}$ load (or DIN concentration) in winter and early spring to a phase when primary production appears to be sensitive to $\mathrm{NO}_{3}$ load in late spring and summer. The shift occurs in March-April when phytoplankton growth rates are already near their maximum values.

This bi-modal pattern supports the previously reported relationships, which focused on spring and summer, i.e. one of the two distinct periods we identified. Lohrenz et al. (1997) used data primarily from late spring and summer in their analysis; no data points for winter and only one early fall data point were included and their only measurement from early spring (March 1991) was excluded (otherwise the resulting relationship was not significant). Lehrter et al. (2009) repeated the analysis after adding 7 more data points (all spring and summer observations) and again found a significant relationship, although with a much smaller $R^{2}=0.20$ instead of $R^{2}=0.58$ in Lohrenz et al. (1997).

The question now is: how can primary production, which is not limited by nutrients in this region, be correlated with nutrient load and concentration? One possibility is that the correlation simply results from the fact that both, primary 

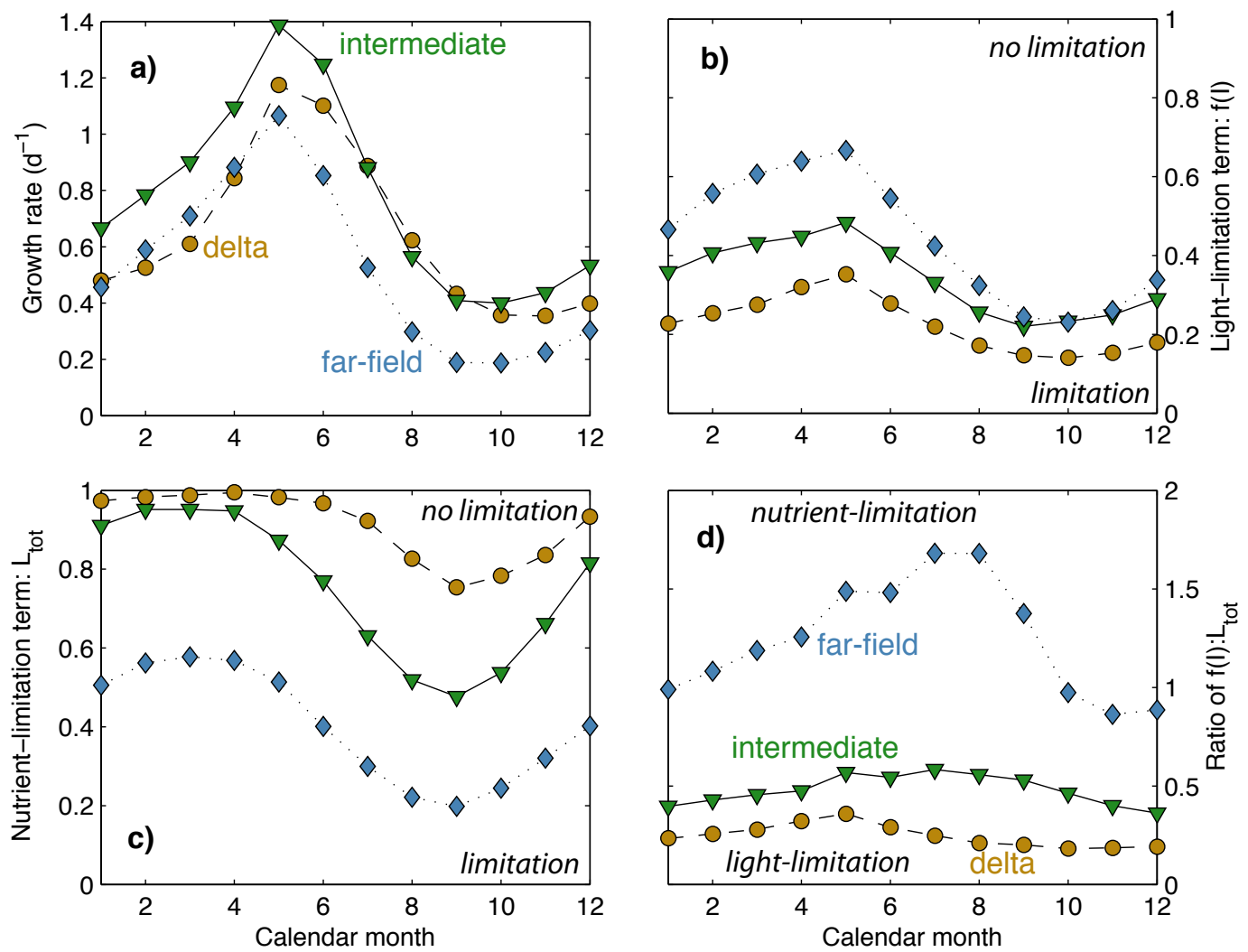

Fig. 13. Monthly climatology of simulated mixed layer mean phytoplankton growth rate (a), light-limitation term (b), nutrient-limitation term (c) and ratio of light- and nutrient-limitation (d) for the delta, intermediate and far-field regions.

production and $\mathrm{NO}_{3}$ load (or DIN concentration) have seasonal cycles. In fact, similar significant correlations result when the average seasonal cycle of primary production and $\mathrm{NO}_{3}$ load (or DIN concentration) is used (Table 1). We thus removed the annual cycle from the time series of monthly primary production and $\mathrm{NO}_{3}$ load (and DIN concentration) and investigated the resulting anomalies for positive correlations (Fig. 15b). A highly significant positive correlation $\left(p<10^{-5}\right)$ between primary production anomalies and $\mathrm{NO}_{3}$ load anomalies for the period from June through September emerges. In other words, interannual differences in $\mathrm{NO}_{3}$ load are reflected in variations in primary production in summer (not in spring). However, when investigating the monthly mean growth rate anomalies of the phytoplankton community, no significant relationship with $\mathrm{NO}_{3}$ load anomalies (and DIN concentration anomalies) exists (Fig. 15c). The lack of a relationship between nutrient load (or concentration) and community growth rates is consistent with our expectation that a phytoplankton community that is not limited by nutrients also should not be sensitive to perturbations in nutrient concentrations. Considering that primary production is the product of instantaneous phytoplankton growth rate and accumulated phytoplankton biomass, the relationship between primary production and $\mathrm{NO}_{3}$ load could simply reflect a relationship between accumulated phytoplankton biomass and $\mathrm{NO}_{3}$ load (or concentration). In fact, there is a highly significant relationship $\left(p<10^{-13}\right)$ between monthly phytoplankton biomass anomalies and $\mathrm{NO}_{3}$ load for June through September (Fig. 15d). Thus, the positive correlation between primary production and $\mathrm{NO}_{3}$ load in the light-limited region of the plume results primarily from increased accumulation of phytoplankton in years with higher discharge and $\mathrm{N}$ input, possibly due to differences in loss terms (i.e., advection and mixing, grazing and sedimentation).

For example, changes in freshwater input likely cause altered circulation patterns over the shelf. Increased accumulation during anomalously high streamflow years (corresponding to high $\mathrm{NO}_{3}$ load because $\mathrm{NO}_{3}$ load and streamflow are correlated) suggests that a retaining circulation pattern is formed during wetter years. One possible mechanism is the enhancement of a recirculating gyre east of the Mississippi River delta (Ichiye, 1960; Wiseman Jr et al., 1982; Hetland and DiMarco, 2008). Fong and Geyer (2002) demonstrated the counter-intuitive result that increased river flow will decrease downstream coastal current transport, thereby increasing retention in the recirculating bulge that forms offshore of a freshwater source. Investigation into the potential causes of hydrodynamic retention of plankton under high discharge 

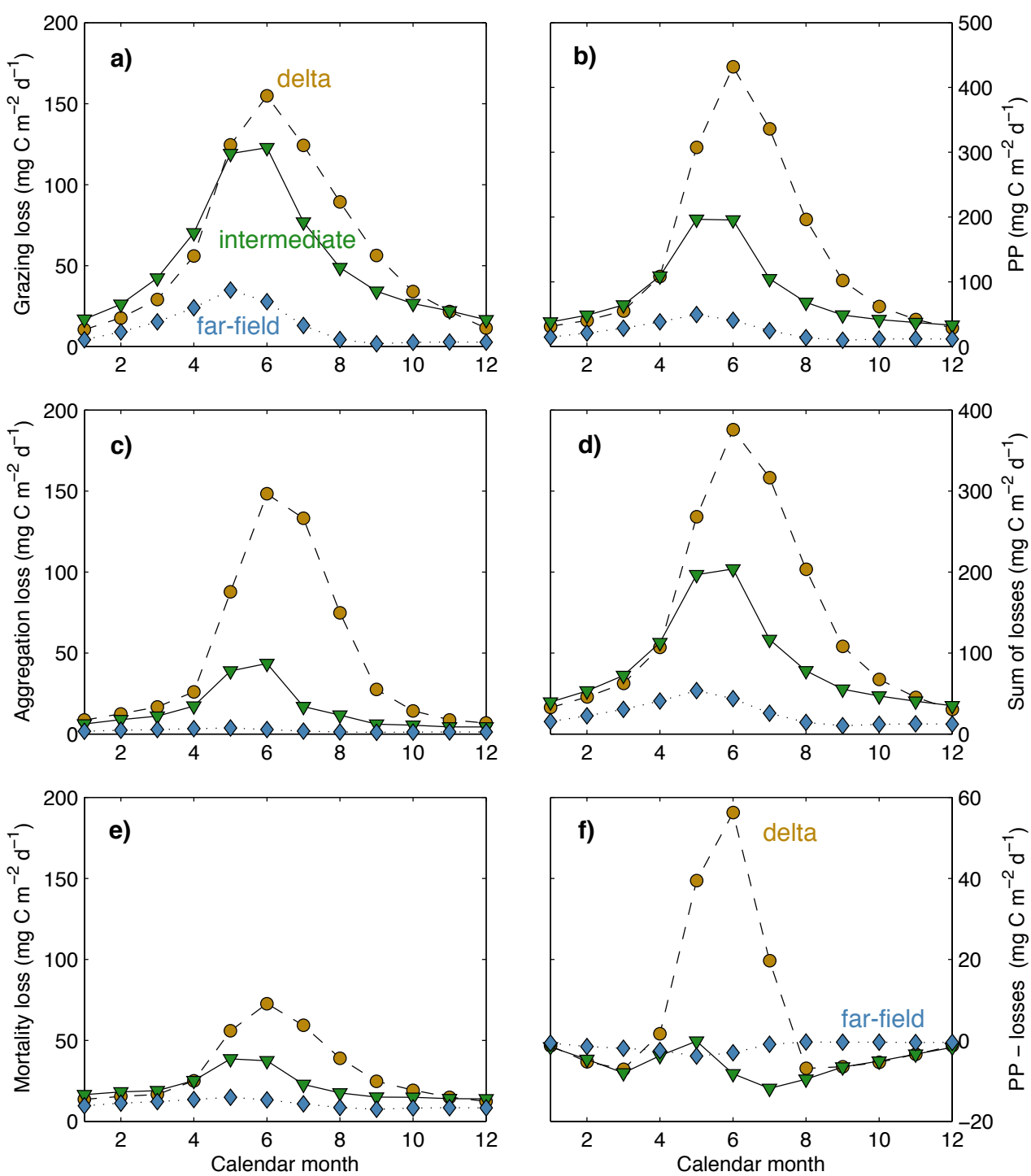

Fig. 14. Monthly climatology of simulated mixed layer mean phytoplankton loss due to grazing (a), aggregation (c), and mortality (e). Also shown is monthly mixed layer mean primary production (b), sum of the three biological phytoplankton loss terms (d) and balance of primary production and biological loss terms (f). The losses were converted from units of mmol N m${ }^{-3}$ to $\mathrm{mg} \mathrm{C} \mathrm{m}^{-3}$ assuming the Redfield ratio of $106 \mathrm{C}$ to $16 \mathrm{~N}$ and using the molar mass of nitrogen.

conditions is beyond the scope of this paper, and will be the focus of future studies.

\section{Conclusions}

We presented a 15-yr simulation of a realistic physicalbiological model for the Texas-Louisiana Shelf. Our model describes the spatial and temporal patterns of nitrate and phytoplankton in agreement with observations and predicts rates of primary production and grazing that agree with experimentally determined rates. In the model, differences in phytoplankton biomass and primary production across the ecological gradient from the delta, via the intermediate, to the far-field region appear to be driven primarily by differences in phytoplankton losses. For example, while phytoplankton growth rates are systematically lower in the delta region compared to the intermediate region, phytoplankton biomass and primary production is markedly higher. This can be explained by differences in the phytoplankton loss terms.

Our model shows that the existence of a statistically significant correlation between primary production and nitrogen load in the delta region near the Mississippi River delta does not reflect a direct stimulation of phytoplankton growth rates by nutrients as expected given the lack of nutrient-limitation in this region. When investigating this relationship it is necessary to first remove the seasonal cycle or, since this is less 
a)
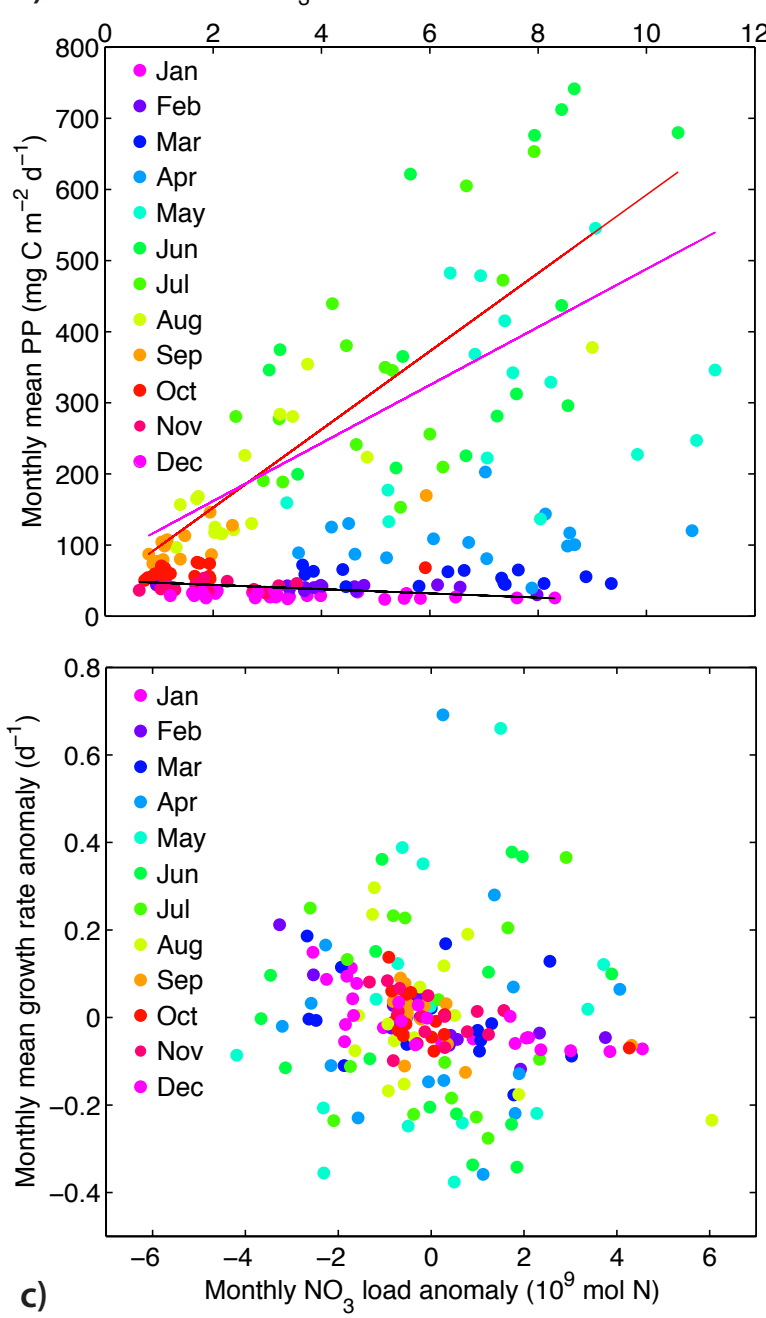

b) Monthly $\mathrm{NO}_{3}$ load anomaly $\left(10^{9} \mathrm{~mol} \mathrm{~N}\right)$
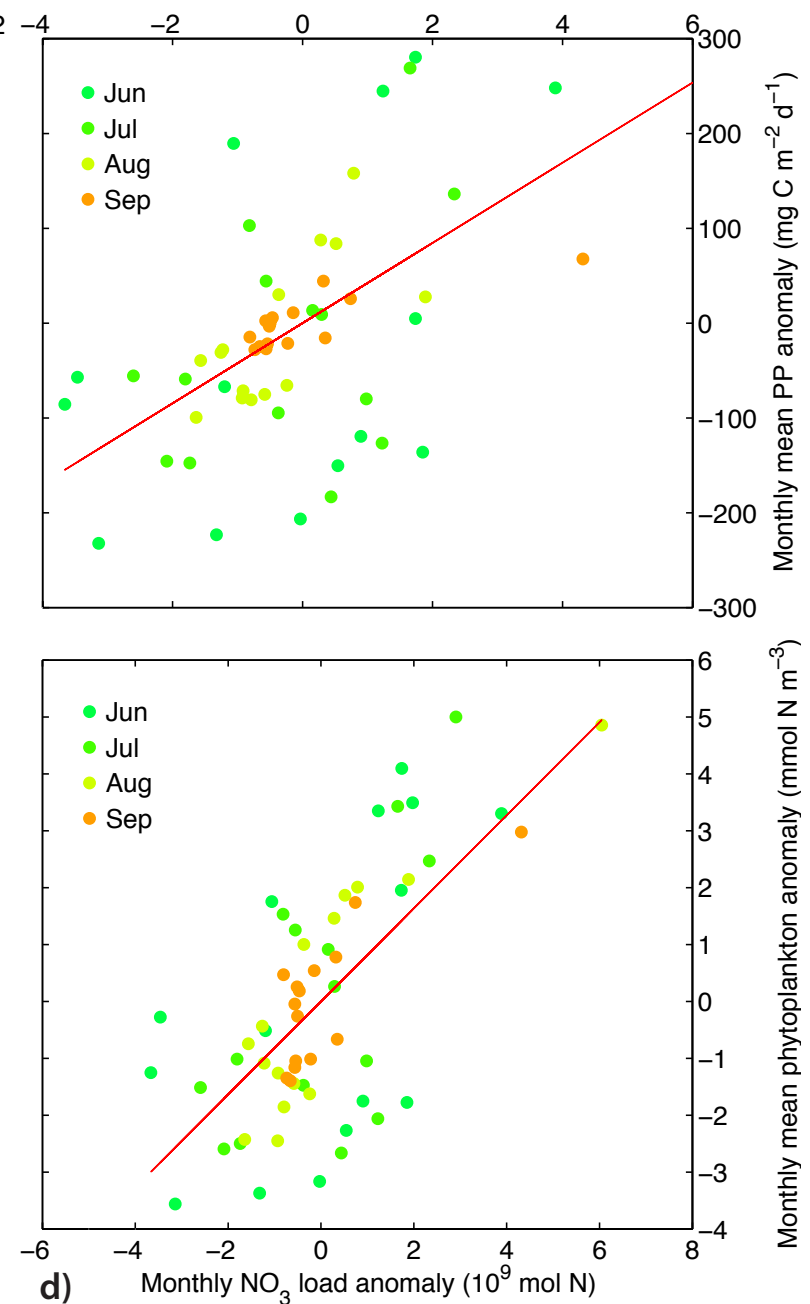

Fig. 15. Simulated monthly mean variables for the delta region plotted over monthly $\mathrm{NO}_{3}$ load from the Mississippi River for the simulation period from January 1990 to December 2004. (a) Primary production over $\mathrm{NO}_{3}$ load (colored dots) and their linear regressions (solid lines) for June through September (red), May through September (magenta) and October through February (black). (b) Anomaly of primary production over anomaly of $\mathrm{NO}_{3}$ load for June through September (colored dots) and their linear regression (red line). (c) Anomaly of phytoplankton growth rate over anomaly $\mathrm{NO}_{3}$ load. (d) Anomaly of phytoplankton biomass over anomaly of $\mathrm{NO}_{3}$ load (colored dots) and their linear regression (red line). Regression parameters are given in Table 1.

practical with sparse observational data sets, take into account the autocorrelation between primary production and nitrogen load by increasing the degrees of freedom and adjusting the $p$-levels appropriately. We find a statistically significant relationship between anomalies of primary production and nitrogen load for the months of June through September. We also find a statistically significant relationship between the anomalies of phytoplankton biomass and nitrogen load for the same months, but not for the anomalies of phytoplankton growth rates and nitrogen load. Since primary production is the product of growth rate and phytoplankton biomass the relationship between primary production and nitrogen load simply reflects the relationship between phytoplankton biomass and nitrogen load, which results from differences in phytoplankton accumulation likely due to differences in loss terms.

Acknowledgements. We thank Jason Sylvan and James Ammerman for making their nutrient data available to us and John Lehrter, Mike Dagg and two anonymous reviewers for their constructive criticism on an earlier version of this manuscript. This work was supported by NOAA CSCOR grants NA06N0S4780198 and NA09N0S4780208 and Cooperative Agreement M07AC12922 with the US Department of the Interior (Minerals Management Service). NOAA NGOMEX publication no. 141.

Edited by: J. Middelburg 


\section{References}

Aulenbach, B., Buxton, H., Battaglin, W., and Coupe, R.: Streamflow and nutrient fluxes of the Mississippi-Atchafalaya River Basin and subbasins for the period of record through 2005, Openfile report 2007-1080, US Geological Survey, 2007.

Bianchi, T., DiMarco, S., Smith, R., and Schreiner, K.: A gradient of dissolved organic carbon and lignin from TerrebonneTimbalier Bay estuary to the Louisiana shelf (USA), Mar. Chem., 117, 32-41, 2009.

Bianchi, T., DiMarco, S., Cowan Jr., J., Hetland, R., Chapman, P., Day, J., and Allison, M.: The science of hypoxia in the Northern Gulf of Mexico: a review, Sci. Total Environ., 408, 1471-1484, 2010.

Boyer, T. P., Antonov, J. I., Garcia, H. E., Johnson, D. R., Locarnini, R. A., Mishonov, A. V., Pitcher, M. T., Baranova, O. K., and Smolyar, I. V.: World Ocean Database 2005, edited by: Levitus, S., NOAA Atlas NESDIS 60, US Government Printing Office, Washington, DC, 190 pp., DVDs, 2006.

da Silva, A., Young-Molling, C., and Levitus, S.: Atlas of surface marine data 1994, vol. 3. Anomalies of fluxes of heat and momentum, NOAA Atlas NESDIS 8, Natl. Oceanic and Atmos. Admin., Silver Spring, MD, 1994a.

da Silva, A., Young-Molling, C., and Levitus, S.: Atlas of surface marine data 1994, vol. 4, Anomalies of fresh water fluxes, NOAA Atlas NESDIS 9, Natl. Oceanic and Atmos. Admin., Silver Spring, MD, 1994b.

Dagg, M.: Copepod grazing and the fate of phytoplankton in the Northern Gulf of Mexico, Cont. Shelf Res., 15, 1303-1317, 1995.

David, M., Drinkwater, L., and McIsaac, G.: Sources of nitrate yields in the Mississippi River Basin, J. Environ. Qual., 39, 1657-1667, 2010.

Devol, A. H.: Denitrification including anammox, chapt. 6: in: Nitrogen in the Marine Environment, edited by: Capone, D., Carpenter, E., Mullholland, M., and Bronk, D., Elsevier, Burlington, Amsterdam, San Diego, London, 263-302, 2008.

DiMarco, S. and Reid, R.: Characterization of the principal tidal current constituents on the Texas-Louisiana shelf, J. Geophys. Res., 103, 3093-3109, 1998.

DiMarco, S., Chapman, P., Walker, N., and Hetland, R.: Does local topography control hypoxia on the Eastern Texas-Louisiana shelf?, J. Marine Syst., 80, 25-35, 2010.

Eldridge, P. and Roelke, D.: Origins and scales of hypoxia on the Louisiana shelf: importance of seasonal plankton dynamics and river nutrients and discharge, Ecol. Model., 221, 1028-1042, 2010.

Fahnenstiel, G., McCormick, M., Lang, G., Redalje, D., Lohrenz, S., Markowitz, M., Wagoner, B., and Carrick, H.: Taxon-specific growth and loss rates for dominant phytoplankton populations from the Northern Gulf of Mexico, Mar. Ecol.-Prog. Ser., 117, 229-239, 1995.

Fennel, K., Wilkin, J., Levin, J., Moisan, J., O’Reilly, J., and Haidvogel, D.: Nitrogen cycling in the Middle Atlantic Bight: results from a three-dimensional model and implications for the North Atlantic nitrogen budget, Global Biogeochem. Cy., 20, GB3007, doi:10.1029/2005GB002456, 2006.

Fennel, K., Wilkin, J., Previdi, M., and Najjar, R.: Denitrification effects on air-sea $\mathrm{CO}_{2}$ flux in the coastal ocean: simulations for the Northwest North Atlantic, Geophys. Res. Lett., 35, L24608,
doi:10.1029/2008GL036147, 2008.

Fennel, K., Brady, D., DiToro, D., Fulweiler, R., Gardner, W., Giblin, A., McCarthy, M., Rao, A., Seitzinger, S., ThouvenotKorppoo, M., and Tobias, C.: Modeling denitrification in aquatic sediments, Biogeochemistry, 93, 159-178, 2009.

Flather, R.: A tidal model of the Northwest European continental shelf, Mem. Soc. R. Sci. Liege, 10, 141-164, 1976.

Fong, D. and Geyer, W.: The alongshore transport of freshwater in a surface-trapped river plume, J. Phys. Oceanogr., 32, 957-972, 2002.

Goolsby, D., Battaglin, W., Aulenbach, B., and Hooper, R.: Nitrogen flux and sources in the Mississippi River Basin, Sci. Total Environ., 248, 75-86, 2000.

Green, R., Breed, G., Dagg, M., and Lohrenz, S.: Modeling the response of primary production and sedimentation to variable nitrate loading in the Mississippi River plume, Cont. Shelf Res., 28, 1451-1465, 2008.

Greene, R., Lehrter, J., and Hagy, J.: Multiple regression models for hindcasting and forecasting midsummer hypoxia in the Gulf of Mexico, Ecol. Appl., 19, 1161-1175, 2009.

Gruber, N., Frenzel, H., Doney, S., Marchesiello, P., McWilliams, J., Moisan, J., Oram, J., Plattner, G., and Stolzenbach, K.: Eddy-resolving simulation of plankton ecosystem dynamics in the California Current System, Deep-Sea Res. Pt. I, 53, 1483-1516, 2006.

Haidvogel, D. B., Arango, H., Budgell, W. P., Cornuelle, B. D., Curchitser, E., Di Lorenzo, E., Fennel, K., Geyer, W. R., Hermann, A. J., Lanerolle, L., Levin, J., McWilliams, J. C., Miller, A. J., Moore, A. M., Powell, T. M., Shchepetkin, A. F., Sherwood, C. R., Signell, R. P., Warner, J. C., and Wilkin, J.: Ocean forecasting in terrain-following coordinates: formulation and skill assessment of the regional ocean modeling system, J. Comput. Phys., 227, 3595-3624, 2008.

Hetland, R. and DiMarco, S.: How does the character of oxygen demand control the structure of hypoxia on the Texas-Louisiana continental shelf?, J. Marine Syst., 70, 49-62, 2008.

Hetland, R. and DiMarco, S.: Skill assessment of a hydrodynamic model of circulation over the Texas-Louisiana continental shelf, Ocean Modell., submitted, 2011.

Ichiye, T.: On the hydrography of the Mississippi Delta, Oceanogr. Mag., 11, 65-78, 1960.

Jochens, A., DiMarco, S., Nowlin Jr., W. D., Reid, R., and Kennicutt II, M.: Northeastern Gulf of Mexico chemical oceanography and hydrography study, Synthesis report, OCS study MMS 2002, Tech. rep., US Department of the Interior, Minerals Management Service, Gulf of Mexico OCS Region, New Orleans, LA, 2002.

Lehrter, J., Murrell, M., and Kurtz, J.: Interactions between freshwater input, light, and phytoplankton dynamics on the Louisiana continental shelf, Cont. Shelf Res., 29, 1861-1872, 2009.

Lohrenz, S., Fahnenstiel, G., Redalje, D., Lang, G., Chen, X., and Dagg, M.: Variations in primary production of Northern Gulf of Mexico continental shelf waters linked to nutrient inputs from the Mississippi River, Mar. Ecol.-Prog. Ser., 155, 45-54, 1997.

Lohrenz, S., Fahnenstiel, G., Redalje, D., Lang, G., Dagg, M., Whitledge, T., and Dortch, Q.: Nutrients, irradiance, and mixing as factors regulating primary production in coastal waters impacted by the Mississippi River plume, Cont. Shelf Res., 19, 1113-1141, 1999.

Marchesiello, P., McWilliams, J. C., and Shchepetkin, A.: Open 
boundary condition for long-term integration of regional oceanic models, Ocean Modell., 3, 1-20, 2001.

Mellor, G. and Yamada, T.: Development of a turbulence closure model for geophysical fluid problems, Rev. Geophys., 20, 851875, 1982.

Milliman, J. and Meade, R.: World-wide delivery of river sediment to the oceans, J. Geol., 91, 1-21, 1983.

Morse, J. and Rowe, G.: Benthic biogeochemistry beneath the Mississippi River plume, Estuar. Coast., 22, 206-214, 1999.

Nowlin Jr., W. D., Jochens, A. E., Reid, R. O., and DiMarco, S. F.: Texas-Louisiana shelf circulation and transport processes study, Synthesis report. Vol. I and II. OCS study MMS 98-0035 and MMS 98-0036, Tech. rep., US Department of the Interior, Minerals Management Service, Gulf of Mexico OCS Regional Office, New Orleans, LA, 1998.

Oschlies, A.: Improved representation of upper-ocean dynamics and mixed layer depths in a model of the North Atlantic on switching from eddy-permitting to eddy-resolving grid resolution, J. Phys. Oceanogr., 32, 2277-2298, 2002.

Peña, M. A., Katsev, S., Oguz, T., and Gilbert, D.: Modeling dissolved oxygen dynamics and hypoxia, Biogeosciences, 7, 933957, doi:10.5194/bg-7-933-2010, 2010.

Rabalais, N., Turner, R., and Wiseman Jr., W.: Gulf of Mexico Hypoxia, aka "The Dead Zone”, Ann. Rev. Ecol. Syst., 33, 235-263, 2002.

Rowe, G. and Chapman, P.: Continental shelf hypoxia: some nagging questions, Gulf Mexico Sci., 20, 153-160, 2002.
Seitzinger, S. and Giblin, A.: Estimating denitrification in North Atlantic continental shelf sediments, Biogeochemistry, 35, 235260, 1996.

Sylvan, J., Dortch, Q., Nelson, D., Brown, A., Morrison, W., and Ammerman, J.: Phosphorus limits phytoplankton growth on the Louisiana shelf during the period of hypoxia formation, Environ. Sci. Technol, 40, 7548-7553, 2006.

Turner, R., Rabalais, N., Swenson, E., Kasprzak, M., and Romaire, T.: Summer hypoxia in the Northern Gulf of Mexico and its prediction from 1978 to 1995, Mar. Environ. Res., 59, 65-77, 2005.

Walker, N. and Rabalais, N.: Relationships among satellite chlorophyll- $a$, river inputs, and hypoxia on the Louisiana continental shelf, Gulf of Mexico, Estuar. Coast., 29, 1081-1093, 2006.

Wang, W., Nowlin Jr., W., and Reid, R.: Analyzed surface meteorological fields over the Northwestern Gulf of Mexico for 1992-94: mean, seasonal, and monthly patterns, Mon. Weather Rev., 126, 2864-2883, 1998.

Wiseman Jr., W., Murray, S., Bane, J., and Tubman, M.: Physical environment of the Louisiana Bight, Contrib. Mar. Sci., 25, 109$120,1982$.

Wiseman, W., Rabalais, N., Turner, R., Dinnel, S., and MacNaughton, A.: Seasonal and interannual variability within the Louisiana coastal current: stratification and hypoxia, J. Marine Syst., 12, 237-248, 1997. 